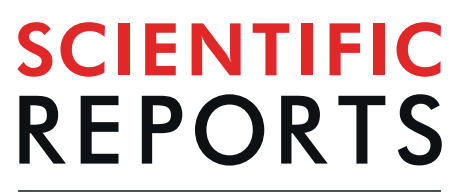

\title{
OPEN Aerobic and anaerobic removal of lead and mercury via calcium carbonate precipitation mediated by statistically optimized nitrate reductases
}

\begin{abstract}
Marwa Eltarahony*, Sahar Zaki \& Desouky Abd-El-Haleem
The nonbiodegradability nature of heavy metals renders them resident in food chain and subsequently, destructing the entire ecosystem. Therefore, this study aimed to employ nitrate reduction-driven calcium carbonate precipitation in remediation of lead and mercury aerobically and anaerobically by Proteus mirabilis 10B, for the first time. Initially, Plackett-Burman design was employed to screen of 16 independent variables for their significances on periplasmic (NAP) and membrane-bound (NAR) nitrate reductases. The levels for five significant variables and their interaction effects were further optimized by central composite design. The maximum activities of NAP and NAR recorded 2450 and $3050 \mathrm{U} / \mathrm{mL}$ by 2 -fold enhancement, comparing with non-optimized medium. Under aerobic and anaerobic optimized remediation conditions, the changes in media chemistry revealed positive correlation among bacterial growth, nitrate reductase activity, $\mathrm{pH}_{1} \mathrm{NO}_{3}{ }^{-}$and $\mathrm{NO}_{2}{ }^{-}$consumption and removal of $\mathrm{Ca}^{2+}$, $\mathrm{Pb}^{2+}$ and $\mathrm{Hg}^{2+}$. Subsequently, the remediated precipitates were subjected to mineralogical analysis; energy dispersive $X$-ray patterns exhibited characteristic peaks of $\mathrm{C}, \mathrm{O}$ and $\mathrm{Ca}$ in addition to $\mathrm{Pb}$ and $\mathrm{Hg}$. Scanning electron microscope depicted the presence of bacterial imprints and protrusions on rough and smooth surface bioliths. However, $\mathrm{X}$-ray diffraction indicated entrapment of $\mathrm{PbCO}_{3}, \mathrm{~Pb}_{2} \mathrm{O}, \mathrm{CaPbO}_{3}$, $\mathrm{Hg}$ and $\mathrm{Hg}_{2} \mathrm{O}$ in calcite lattice. Interestingly, such approach is feasible, efficient, cost-effective and ecofriendly for heavy metals remediation.
\end{abstract}

Pollution with heavy metals is serious environmental concern, especially with continuous growing in urbanization and rapid pace in population which are synchronized with progressive increase in industrialization. Lead $(\mathrm{Pb})$ and mercury $(\mathrm{Hg})$ are among the "big three" heavy metals, possessing density more than $5 \mathrm{~g} / \mathrm{cm}^{3}$, which enters environment as industrial effluents ${ }^{1}$. The anthropogenic activities such as electroplating, painting, textile manufacturing, smelting, mine drainage, metallurgy, batteries production, construction, medical treatments, military and coal burning are the major sources of hazardous lead and mercury byproducts ${ }^{2}$. Indeed, the real hazard caused by lead and mercury are assigned to their nonbiodegradability and hence accumulate persistently in the food chain causing severe impact on all living organisms ${ }^{3}$. In general, the neurological disorders, heart disease, permanent brain damage and behavioral abnormalities are the common symptoms of lead toxicity in adults and children. Whereas, Minamata's disease is one of the most common diseases caused by mercury toxicity ${ }^{4,5}$.

Therefore, there is an urgent need to employ the appropriate method to detoxify these metals from any contaminated wastes or discharges. Recently, conventional remediation techniques were utilized to eliminate them from contaminated environments such as chemical precipitation, evaporation, electrochemical treatment, oxidation/reduction, carbon adsorption, ion exchange, membrane filtration and reverse osmosis ${ }^{6,7}$. Unfortunately, such methods suffer from several limitations such as capital-intensive, less effective and consuming a lot of chemicals and energy as revealed by Bojórquez et al. ${ }^{8}$ and Tariq et al. ${ }^{9}$. Alternatively, many biological remediation approaches have been introduced proving their efficiency in economic manner as well as environmental

Environmental Biotechnology Department, Genetic Engineering and Biotechnology Research Institute (GEBRI), City of Scientific Research and Technological Applications (SRTA-City), 21934, New Borg El-Arab City, Alexandria, Egypt. *email: m_eltarahony@yahoo.com 
friendliness ${ }^{10}$. The bioremediation approach includes the employment of plants, microorganisms, dead biomass or viable cells ${ }^{11}$. However, several studies documented the efficiency of phytoremediation of soil contaminated with different heavy metals, but harsh and dry climate in arid regions limited its applications ${ }^{12}$. Besides, the bioaccumulation, biosorption, bioleaching, biocoagulation and bioflocculation are categorized among biological remediation strategies. The major drawback associated with such methods is the possibility of releasing the adsorbed heavy metals back to the environment ${ }^{13}$. Thus, the biomineralization process considers being an alternative and appropriate method to constrain heavy metals away from the surrounding environment ${ }^{14}$.

Biomineralization or microbially induced carbonate precipitation (MICP) is defined as bioprecipitation of calcium carbonate mineral by the virtue of microbial cells and their biochemical activities. The alkalinity engine and nucleation sites are the fundamental key factors dictated such process ${ }^{15}$. During microbial growth and metabolism activation in MICP process, the microbes are able to generate carbonate compounds $\left(\mathrm{CO}_{3}{ }^{2-}\right)$ that react with calcium ions $\left(\mathrm{Ca}^{2+}\right)$ producing $\mathrm{CaCO}_{3}$ mineral precipitates ${ }^{16}$. Accordingly, the heavy metals with ionic radius approximate $\mathrm{Ca}^{2+}$ such as $\mathrm{Pb}^{2+}$ and $\mathrm{Hg}^{2+}$ can be incorporated in $\mathrm{CaCO}_{3}$ lattice and substituting $\mathrm{Ca}^{2+}$ ions. In such way, MICP traps heavy metals, preventing them from liberation in ambient environment ${ }^{14}$. In addition to pollutants bioremediation, several applications were addressed for MICP such as oil recovery, $\mathrm{CO}_{2}$ capturing, soil reinforcement, bioplugging/biocementation of rocks, self-healing of concrete structure and restoration of statuary and historical buildings ${ }^{15,17}$.

MICP occurs naturally by diverse microbial species in different environmental conditions through various metabolic pathways, including photosynthesis, oxidative deamination of amino acids, nitrate reduction, urea degradation, sulfate reduction, methane oxidation and extracellular polymeric substances ${ }^{17,18}$. Generally, Synechococcus cyanobacteria, Chlorella sp. ${ }^{19}$, Desulfovibrio desulfuricans ${ }^{20}$, Bacillus spharicus ${ }^{17}$, Sporosarcina sp..$^{18}$, Arthrobacter crystallopoietes, Rhodococcus qingshengii, Psychrobacillus psychrodurans ${ }^{21}$ and Verticillium $s p .{ }^{22}$ are examples on different microbial groups possessing the ability to induce $\mathrm{CaCO}_{3}$ precipitation.

It is worth noting that various microbial genera are able to utilize nitrate aerobically and anaerobically by the dint of periplasmic (NAP) and membrane-bound nitrate reductase (NAR), respectively. Thus, they exhibit flexibility in their growth strategy and energy generation; encouraging the exploitation of bacterial nitrate dissimilation in bioremediation of nitrate pollution and detoxification of metals simultaneously in an eco-friendly approach and under different oxygen level. Despite of carbonate yield generated by nitrate dissimilation process is higher than ureolysis (approximately two-fold) and the highly negative standard Gibbs free energy $\left(\Delta \mathrm{G}^{\circ}=785 \mathrm{~kJ} /\right.$ $\mathrm{mol}$ ) provided by it, the published studies about MICP through nitrate dissimilation was limited ${ }^{23}$. As elucidated by Zhu and Dittrich ${ }^{24}$, the published researches about MICP through photosynthesis, ureolysis, nitrate reduction, sulfate reduction, and methane oxidation were $1128,120,34,110$, and 44 , respectively. Where, the predominant metabolic activity for MICP accounted in terrestrial and aquatic environments (freshwater and marine) were $43 \%$ and $38 \%$ for ureolysis and photosynthesis, respectively.

Accordingly, this study was conducted to eliminate $\mathrm{Pb}^{2+}$ and $\mathrm{Hg}^{2+}$ in MICP through aerobic and anaerobic nitrate utilization process. It initiated by maximizing NAP and NAR (the key enzymes for MICP) activities using the optimization statistical approach. Subsequently, under optimized conditions, the precipitation of both metals via MICP process under nitrate dissimilation conditions (aerobically and anaerobically) was assessed and confirmed using energy dispersive X-ray spectrometry (EDS), scanning electron microscopy (SEM) and X-ray diffraction (XRD). In this sense, as far as we know, no study reported before about $\mathrm{Pb}^{2+}$ and $\mathrm{Hg}^{2+}$ sequestration using MICP through nitrate reduction pathway of Proteus mirabilis under aerobic and anaerobic conditions.

\section{Results and Discussion}

Optimization of NAP and NAR activities by design of experiment (DOE). Evaluation of nutritional/environmental factors affecting NAP and NAR activities using plackett-burman design (PBD). PBD experiments showed a markedly wide variation in the activities of both enzymes, ranging from $9.14 \mathrm{U} / \mathrm{mL}$ to $864.29 \mathrm{U} /$ $\mathrm{mL}$ for NAP and $85.71 \mathrm{U} / \mathrm{mL}$ to $1322.86 \mathrm{U} / \mathrm{mL}$ for NAR along with 20 experimental runs (Tables 1 and 2); this variation reflected the importance of media optimization to attain higher enzyme activity. The multiple linear regression coefficients of the model were analyzed statistically by MINITAB 14 using the student's t-test. The $p$-values are used to check the consequences and significance of each independent variable within the design (Supplementary Tables S1 and S2). Commonly, the larger magnitude of T-value with 'a low probability ' $P$ ' value ( rob $>\mathrm{F}<0.05$ ) indicates high significance of the corresponding coefficient ${ }^{25,26}$.

On the basis of calculated $p$-value, $\mathrm{FeCl}_{2} \cdot 4 \mathrm{H}_{2} \mathrm{O}$ ( $p$-value, 0.004 ), $\mathrm{Na}_{2} \mathrm{MoO}_{4} \cdot 2 \mathrm{H}_{2} \mathrm{O}$ ( $p$-value, 0.002 ), sodium citrate ( $p$-value, 0.006$)$, inoculum size (\%) ( $p$-value, 0.009$)$ and $\mathrm{pH}$ ( $p$-value, 0.009$)$ were considered to be the significant media components that influenced NAP activity, as clearly illustrated in the probability plot of effects and in the Pareto charts (Supplementary Fig. S3-A,B). The probability plot of effects is very important for separating random noise from real effects based on their distribution on the plot. Where, all significant factors that have the largest effect on response lie furthest from the line, while the rest of the factors, which lie along the line, are negligible. Accordingly, $\mathrm{FeCl}_{2} \cdot 4 \mathrm{H}_{2} \mathrm{O}, \mathrm{Na}_{2} \mathrm{MoO}_{4} \cdot 2 \mathrm{H}_{2} \mathrm{O}$, sodium citrate contributed positively to NAP activity (higher concentration of these components was accompanied by increased NAP activity) since these lied on the right-hand side of the line. Whereas, $\mathrm{pH}$ and inoculum size (\%) negatively affected NAP activity (i.e. increasing in NAP activity was associated with low values of these parameters) as seen as lying on the left-hand side of the line.

On the other hand, $\mathrm{FeCl}_{2} \cdot 4 \mathrm{H}_{2} \mathrm{O}$ ( $p$-value 0.004 ), sodium citrate (C-source and electron donor; $p$-value, $0.013), \mathrm{NaNO}_{3}(\mathrm{~N}$-source and electron acceptor; $p$-value, 0.026$), \mathrm{Na}_{2} \mathrm{MoO}_{4} \cdot 2 \mathrm{H}_{2} \mathrm{O}(p$-value, 0.042$)$ and $\mathrm{pH}(p$ -value, 0.028) were the most significant factors affecting NAR activity. As noticed, $\mathrm{FeCl}_{2} \cdot 4 \mathrm{H}_{2} \mathrm{O}, \mathrm{Na}_{2} \mathrm{MoO}_{4} \cdot 2 \mathrm{H}_{2} \mathrm{O}$, $\mathrm{NaNO}_{3}$ and sodium citrate positively influenced NAR activity and $\mathrm{pH}$ influenced negatively (Supplementary Fig. S4-A). The order of significance was highlighted from a Pareto chart (Supplementary Fig. S4-B).

The standard analysis of variance (ANOVA) indicated that both models were significant in term of small $p$-value $(P<0.05)$, with values of 0.015 and 0.035 obtained for NAP and NAR, respectively (Supplementary Table S5). For examining the overall performance of the model, the coefficient of determination $\left(\mathrm{R}^{2}\right)$ was 


\begin{tabular}{|c|c|c|c|c|c|c|c|c|c|c|c|c|c|c|c|c|c|c|c|}
\hline $\begin{array}{l}\text { Run } \\
\text { Order }\end{array}$ & $\begin{array}{l}\mathrm{X} 1 \\
\mathrm{pH}\end{array}$ & \begin{tabular}{|l|} 
X2 \\
Inoculum \\
Size \%
\end{tabular} & $\begin{array}{l}\mathrm{X3} \\
\mathrm{FeCl}_{2} . \\
4 \mathrm{H}_{2} \mathrm{O} \\
(\mathrm{mg})\end{array}$ & \begin{tabular}{|l|}
$\mathrm{X} 4$ \\
$\mathrm{CuSO}_{4 \cdot}$ \\
$5 \mathrm{5H}_{2} \mathrm{O}$ \\
$(\mathrm{mg})$ \\
\end{tabular} & \begin{tabular}{l|}
$\mathrm{X} 5$ \\
$\mathrm{MnCl}_{2} \cdot$ \\
$4 \mathrm{H}_{2} \mathrm{O}$ \\
$(\mathrm{mg})$
\end{tabular} & $\begin{array}{l}\text { X6 Sodium } \\
\text { Citrate }(\mathrm{g})\end{array}$ & \begin{tabular}{|l|}
$\mathrm{X} 7$ \\
$\mathrm{~K}_{2} \mathrm{HPO}_{4}$ \\
$(\mathrm{~g})$
\end{tabular} & $\begin{array}{l}\mathrm{X8} \\
\mathrm{MgSO}_{4} \\
(\mathrm{mg})\end{array}$ & $\begin{array}{l}\mathrm{X9} \\
\mathrm{ZnSO}_{4} \cdot \\
7 \mathrm{H}_{2} \mathrm{O} \\
(\mathrm{mg})\end{array}$ & \begin{tabular}{|l|}
$\mathrm{X10}$ \\
$\mathrm{CoCl}_{2} \cdot$ \\
$6 \mathrm{H}_{2} \mathrm{O}$ \\
$(\mathrm{mg})$
\end{tabular} & \begin{tabular}{|l|}
$\mathrm{X} 11$ \\
$\mathrm{KH}_{2}$ \\
$\mathrm{PO}_{4}$ \\
$(\mathrm{~g})$
\end{tabular} & \begin{tabular}{|l|} 
X12 \\
Aeration \\
(rpm)
\end{tabular} & \begin{tabular}{|l|}
$\mathrm{X}_{13}$ \\
$\mathrm{H}_{3} \mathrm{BO}_{4}$ \\
$(\mathrm{mg})$
\end{tabular} & $\begin{array}{l}\mathrm{X} 14 \\
\mathrm{Na}^{2} \mathrm{MoO}_{4} . \\
2 \mathrm{H}_{2} \mathrm{O} \\
(\mathrm{mg})\end{array}$ & $\begin{array}{l}\mathrm{X} 15 \\
\mathrm{NaNO}_{3} \\
(\mathrm{~g})\end{array}$ & \begin{tabular}{|l|}
$\mathrm{X} 16$ \\
$\mathrm{NaCl}$ \\
$(\mathrm{g})$
\end{tabular} & $\begin{array}{l}\text { Actual } \\
\text { NAP } \\
\text { Activity } \\
\text { (U/mL) }\end{array}$ & \begin{tabular}{|l|} 
Predicted \\
NAP \\
Activity \\
$(\mathrm{U} / \mathrm{mL})$
\end{tabular} & \begin{tabular}{|l} 
St. \\
Residual
\end{tabular} \\
\hline 1 & 6.5 & 5 & 0 & 0 & 0 & 1 & 0 & 0 & 0 & 0 & 1.5 & 50 & 0 & 0 & 2 & 0 & 117.86 & 127.06 & -0.36 \\
\hline 2 & 6.5 & 15 & 400 & 0 & 90 & 5 & 0 & 0 & 0 & 0 & 4.5 & 50 & 650 & 0 & 7 & 2 & 371.33 & 330.93 & 1.58 \\
\hline 3 & 8.5 & 15 & 0 & 180 & 90 & 1 & 0 & 0 & 0 & 120 & 1.5 & 150 & 0 & 100 & 7 & 2 & 124.29 & 94.06 & 1.18 \\
\hline 4 & 6.5 & 5 & 400 & 0 & 90 & 1 & 3 & 240 & 400 & 120 & 1.5 & 50 & 650 & 100 & 2 & 2 & 451.43 & 421.20 & \begin{tabular}{|l|}
1.18 \\
\end{tabular} \\
\hline 5 & 6.5 & 15 & 400 & 0 & 0 & 1 & 0 & 240 & 0 & 120 & 1.5 & 150 & 650 & 100 & 7 & 0 & 684.29 & 714.52 & -1.18 \\
\hline 6 & 8.5 & 15 & 400 & 0 & 0 & 5 & 3 & 0 & 400 & \begin{tabular}{|l|}
120 \\
\end{tabular} & 1.5 & 50 & 0 & 0 & 7 & 0 & 186.43 & 187.40 & -0.04 \\
\hline 7 & 8.5 & 5 & 0 & 180 & 90 & 1 & 3 & 240 & 0 & 0 & 1.5 & 50 & 650 & 0 & 7 & 0 & 9.14 & -0.06 & 0.36 \\
\hline 8 & 6.5 & 15 & 400 & 180 & 90 & 1 & 0 & 240 & 400 & 0 & 4.5 & 150 & 0 & 0 & 2 & 0 & 263.00 & 263.97 & -0.04 \\
\hline 9 & 6.5 & 15 & 0 & 180 & 90 & 5 & 3 & 0 & 0 & 120 & 4.5 & 50 & 650 & 100 & 2 & 0 & 287.14 & 327.54 & -1.58 \\
\hline 10 & 6.5 & 5 & 400 & 180 & 0 & 5 & 3 & 0 & 0 & 0 & 1.5 & 150 & 0 & 100 & 2 & 2 & 864.29 & 855.09 & 0.36 \\
\hline 11 & 6.5 & 15 & 0 & 180 & 0 & 5 & 3 & 240 & 400 & 0 & 1.5 & 150 & 650 & 0 & 7 & 2 & 219.29 & 228.49 & -0.36 \\
\hline 12 & 8.5 & 5 & 400 & 180 & 0 & 1 & 0 & 0 & 400 & 0 & 4.5 & 50 & 650 & 100 & 7 & 2 & 414.29 & 454.69 & -1.58 \\
\hline 13 & 8.5 & 15 & 0 & 0 & 0 & 1 & 3 & 0 & 400 & 0 & 4.5 & 150 & 650 & 100 & 2 & 0 & 70.43 & 30.03 & 1.58 \\
\hline 14 & 8.5 & 5 & 0 & 0 & 0 & 5 & 0 & 240 & 0 & 120 & 4.5 & 150 & 650 & 0 & 2 & 2 & 238.57 & 239.54 & -0.04 \\
\hline 15 & 8.5 & 15 & 400 & 180 & 0 & 1 & 3 & 240 & 0 & \begin{tabular}{|l|}
120 \\
\end{tabular} & 4.5 & 50 & 0 & 0 & 2 & 2 & 24.53 & 23.56 & 0.04 \\
\hline 16 & 6.5 & 5 & 0 & 180 & 0 & 5 & 0 & 240 & 400 & 120 & 4.5 & 50 & 0 & 100 & 7 & 0 & 797.14 & 756.74 & 1.58 \\
\hline 17 & 6.5 & 5 & 0 & 0 & 90 & 1 & 3 & 0 & 400 & 120 & 4.5 & 150 & 0 & 0 & 7 & 2 & 11.43 & 41.66 & -1.18 \\
\hline 18 & 8.5 & 5 & 400 & 0 & 90 & 5 & 3 & 240 & 0 & 0 & 4.5 & 150 & 0 & 100 & 7 & 0 & 825.71 & 834.91 & -0.36 \\
\hline 19 & 8.5 & 5 & 400 & 180 & 90 & 5 & 0 & 0 & 400 & 120 & 1.5 & 150 & 650 & 0 & 2 & 0 & 332.86 & 331.89 & 0.04 \\
\hline 20 & \begin{tabular}{|l|}
8.5 \\
\end{tabular} & 15 & 0 & 0 & 90 & 5 & 0 & 240 & \begin{tabular}{|l|}
400 \\
\end{tabular} & 0 & 1.5 & 50 & 0 & 100 & 2 & 2 & 64.29 & 94.52 & -1.18 \\
\hline
\end{tabular}

Table 1. Twenty-trial Plackett-Burman matrix for evaluation of independent variables with high/low levels and concentrations along with the actual, predicted NAP activity and studentized residual.

\begin{tabular}{|c|c|c|c|c|c|c|c|c|c|c|c|c|c|c|c|c|c|c|c|}
\hline \begin{tabular}{l|} 
Run \\
Order
\end{tabular} & \begin{tabular}{|l|}
$\mathrm{X} 1$ \\
$\mathrm{KH}_{2} \mathrm{PO}_{4}$ \\
$(\mathrm{~g})$
\end{tabular} & $\begin{array}{l}\mathrm{X} 2 \\
\mathrm{MgSO}_{4} \\
(\mathrm{mg})\end{array}$ & \begin{tabular}{|l}
$\mathrm{X3}$ \\
$\mathrm{NaCl}$ \\
$(\mathrm{g})$
\end{tabular} & \begin{tabular}{|l|}
$\mathrm{X} 4$ \\
$\mathrm{CoCl}_{2} \cdot$ \\
$6 \mathrm{H}_{2} \mathrm{O}$ \\
$(\mathrm{mg})$
\end{tabular} & $\begin{array}{l}\mathrm{X} 5 \\
\mathrm{NaNO}_{3} \\
(\mathrm{~g})\end{array}$ & \begin{tabular}{|l|}
$\mathrm{X} 6$ \\
$\mathrm{FeCl}_{2} \cdot$ \\
$4 \mathrm{H}_{2} \mathrm{O}$ \\
$(\mathrm{mg})$ \\
\end{tabular} & \begin{tabular}{|l|}
$\mathrm{X} 7$ \\
$\mathrm{CuSO}_{4} \cdot$ \\
$5 \mathrm{H}_{2} \mathrm{O}$ \\
$(\mathrm{mg})$ \\
\end{tabular} & \begin{tabular}{|l|}
$\mathrm{X} 8$ \\
$\mathrm{~K}_{2} \mathrm{HPO}_{4}$ \\
$(\mathrm{~g})$ \\
\end{tabular} & $\mathrm{X} 9 \mathrm{pH}$ & \begin{tabular}{|l|}
$\mathrm{X} 10$ \\
$\mathrm{ZnSO}_{4} \cdot$ \\
$7 \mathrm{7H}_{2} \mathrm{O}$ \\
$(\mathrm{mg})$ \\
\end{tabular} & \begin{tabular}{|l|}
$\mathrm{X} 11$ \\
$\mathrm{Na}_{2} \mathrm{MoO}_{4} \cdot$ \\
$2 \mathrm{H}_{2} \mathrm{O}$ \\
$(\mathrm{mg})$ \\
\end{tabular} & \begin{tabular}{|l|}
$\mathrm{X} 12$ \\
$\mathrm{MnCl}_{2} \cdot$ \\
$4 \mathrm{H}_{2} \mathrm{O}$ \\
$(\mathrm{mg})$ \\
\end{tabular} & \begin{tabular}{|l|}
$\mathrm{X} 13$ \\
$\mathrm{H}_{3} \mathrm{BO}_{4}$ \\
$(\mathrm{mg})$
\end{tabular} & \begin{tabular}{|l|} 
X14 \\
Sodium \\
citrate \\
(g) \\
\end{tabular} & \begin{tabular}{|l|} 
X15 \\
Inoculum \\
Size \%
\end{tabular} & \begin{tabular}{|l|} 
X16 \\
Temp. \\
$\left({ }^{\circ} \mathrm{C}\right)$ \\
\end{tabular} & \begin{tabular}{|l|} 
Actual \\
NAR \\
activity \\
(U/mL) \\
\end{tabular} & \begin{tabular}{|l|} 
Predicted \\
NAR \\
Activity \\
$(\mathrm{U} / \mathrm{mL})$ \\
\end{tabular} & $\begin{array}{l}\text { St. } \\
\text { Residua }\end{array}$ \\
\hline 1 & 1.5 & 0 & 0 & 0 & 3 & 0 & 0 & 0 & 6.8 & 0 & 0 & 0 & 0 & 3 & 0.5 & 25 & \begin{tabular}{|l|}
85.71 \\
\end{tabular} & 37.00 & 1.31 \\
\hline 2 & 1.5 & 300 & 1.5 & 0 & 7 & 400 & 0 & 0 & 6.8 & 0 & 100 & 0 & 630 & 3 & 3 & 35 & 820.49 & 854.7 & -0.92 \\
\hline 3 & 4.5 & 300 & 0 & 120 & 7 & 0 & 0 & 0 & 6.8 & 400 & 0 & 90 & 0 & 7 & 3 & 35 & 407.14 & 430.84 & -0.64 \\
\hline 4 & 1.5 & 0 & 1.5 & 0 & 7 & 0 & 180 & 3 & 8.3 & 400 & 0 & 0 & 630 & 7 & 0.5 & 35 & 205.71 & 229.41 & -0.64 \\
\hline 5 & 1.5 & 300 & 1.5 & 0 & 3 & 0 & 0 & 3 & 6.8 & 400 & 0 & 90 & 630 & 7 & 3 & 25 & 287.29 & 263.59 & 0.64 \\
\hline 6 & 4.5 & 300 & 1.5 & 0 & 3 & 400 & 180 & 0 & 8.3 & 400 & 0 & 0 & 0 & 3 & 3 & 25 & 461.71 & 499.91 & -1.02 \\
\hline 7 & 4.5 & 0 & 0 & 120 & 7 & 0 & 180 & 3 & 6.8 & 0 & 0 & 0 & 630 & 3 & 3 & 25 & 189.14 & 237.85 & -1.31 \\
\hline 8 & 1.5 & 300 & 1.5 & 120 & 7 & 0 & 0 & 3 & 8.3 & 0 & 100 & 90 & 0 & 3 & 0.5 & 25 & 165.71 & 203.92 & -1.02 \\
\hline 9 & 1.5 & 300 & 0 & 120 & 7 & 400 & 180 & 0 & 6.8 & 400 & 100 & 0 & 630 & 7 & 0.5 & 25 & 808.57 & 774.36 & 0.92 \\
\hline 10 & 1.5 & 0 & 1.5 & 120 & 3 & 400 & 180 & 0 & 6.8 & 0 & 0 & 90 & 0 & 7 & 0.5 & 35 & 673.57 & 722.28 & -1.31 \\
\hline 11 & 1.5 & 300 & 0 & 120 & 3 & 400 & 180 & 3 & 8.3 & 0 & 0 & 90 & 630 & 3 & 3 & 35 & 324.06 & 275.35 & 1.31 \\
\hline 12 & 4.5 & 0 & 1.5 & 120 & 3 & 0 & 0 & 0 & 8.3 & 0 & 100 & 0 & 630 & 7 & 3 & 35 & 285.71 & 251.52 & 0.92 \\
\hline 13 & 4.5 & 300 & 0 & 0 & 3 & 0 & 180 & 0 & 8.3 & 0 & 100 & 90 & 630 & 7 & 0.5 & 25 & 383.06 & 417.27 & -0.92 \\
\hline 14 & 4.5 & 0 & 0 & 0 & 3 & 400 & 0 & 3 & 6.8 & 400 & 100 & 90 & 630 & 3 & 0.5 & 35 & 289.71 & 327.91 & -1.02 \\
\hline 15 & 4.5 & 300 & 1.5 & 120 & 3 & 0 & 180 & 3 & 6.8 & 400 & 100 & 0 & 0 & 3 & 0.5 & 35 & 281.71 & 243.52 & 1.02 \\
\hline 16 & 1.5 & 0 & 0 & 120 & 3 & 400 & 0 & 3 & 8.3 & 400 & 100 & 0 & 0 & 7 & 3 & 25 & 346.07 & 380.28 & -0.92 \\
\hline 17 & 1.5 & 0 & 0 & 0 & 7 & 0 & 180 & 0 & 8.3 & 400 & 100 & 90 & 0 & 3 & 3 & 35 & 339.01 & 315.31 & 0.64 \\
\hline 18 & 4.5 & 0 & 1.5 & 0 & 7 & 400 & 180 & 3 & 6.8 & 0 & 100 & 90 & 0 & 7 & 3 & 25 & 1322.86 & 1274.15 & 1.31 \\
\hline 19 & 4.5 & 0 & 1.5 & 120 & 7 & 400 & 0 & 0 & 8.3 & 400 & 0 & 90 & 630 & 3 & 0.5 & 25 & 200.00 & 161.81 & 1.02 \\
\hline 20 & 4.5 & 300 & 0 & 0 & 7 & 400 & 0 & 3 & 8.3 & 0 & 0 & 0 & 0 & 7 & 0.5 & 35 & 731.43 & 707.73 & \begin{tabular}{|l|l|}
0.64 \\
\end{tabular} \\
\hline
\end{tabular}

Table 2. Twenty-trial Plackett-Burman matrix for evaluation of independent variables with high/low levels and concentrations along with the actual, predicted NAR activity and studentized residual.

measured. In addition, the adjusted- $R^{2}\left(\right.$ adj- $\left.R^{2}\right)$ value should be in reasonable agreement with $R^{2}$ value ${ }^{27,28}$. The model $\mathrm{R}^{2}$ and adj- $\mathrm{R}^{2}$ values obtained for NAP were 0.9910 and 0.9432 , respectively and those obtained for NAR were 0.9837 and 0.8967 , respectively. These results imply that $99.10 \%$ and $98.37 \%$ of the variability of the data can be explained by the model, and there is only a $0.9 \%$ and $1.63 \%$ chance, which could be due to noise. Both models 
also exhibited good correlation between the observed (experimental) values and the predicted values, as is evident from the studentized residual (Tables 1 and 2). Smaller residual value is preferred (less than \pm 2$)^{29}$. Evidently, the residual values of our models fell within this acceptable range.

The first order model for NAP and NAR activities obtained by ANOVA were fitted to the results obtained from the 20 experiments as highlighted in Eqs. 1 and 2:

$$
\begin{aligned}
\text { NAP Activity }(\mathbf{U} / \mathbf{m L})= & 618-88.8 \mathrm{X} 1-11.8 \mathrm{X} 2+0.620 \mathrm{X} 3+0.175 \mathrm{X} 4-0.974 \mathrm{X} 5 \\
& +50.4 \mathrm{X} 6-15.3 \mathrm{X} 7+332 \mathrm{X} 8-0.184 \mathrm{X} 9-0.068 \mathrm{X} 10+8.31 \mathrm{X} 11 \\
& +0.911 \mathrm{X} 12-0.0308 \mathrm{X} 13+2.81 \mathrm{X} 14+18.6 \mathrm{X} 15-39.5 \mathrm{X} 16 \\
\mathrm{NAR} \text { activity }(\mathbf{U} / \mathbf{m L})= & 438+16.5 \mathrm{X} 1+245 \mathrm{X} 2+53.4 \mathrm{X} 3-1.04 \mathrm{X} 4 \\
+ & 44.3 \mathrm{X} 5+0.837 \mathrm{X} 6+0.761 \mathrm{X} 7-10.7 \mathrm{X} 8-115 \mathrm{X} 9-0.339 \mathrm{X} 10 \\
+ & 1.48 \mathrm{X} 11+0.196 \mathrm{X} 12-0.162 \mathrm{X} 13+57.4 \mathrm{X} 14+24.0 \mathrm{X} 15+1.08 \mathrm{X} 16
\end{aligned}
$$

For further optimization by the central composite design CCD, all variables with a positive effect on NAP and NAR activities were fixed at a high level, and those variables that had negative effect were maintained at a low level.

Central composite design (CCD) for optimization of NAP and NAR activities. To obtain a more precise estimate of the optimal operating conditions, a second order polynomial function was fitted to the experimental results. Thus, the influence of significant variables and interaction effects on the response were investigated. A five-level CCD with 5 independent variables deduced from PBD were applied in a 32-trial matrix. The experimental and the predicted responses along with the design matrix and studentized residual were presented in Table 3 .

As observed with the experimental trials, the NAP and NAR activities varied considerably. The lowest NAP activity $(428.57 \mathrm{U} / \mathrm{mL})$ was recorded in trail number 3 , and the highest activity $(1334.71 \mathrm{U} / \mathrm{mL})$ was observed in trail number 30 . For NAR, the minimum activity $(100 \mathrm{U} / \mathrm{mL})$ was observed in trail number 25 , while the maximum activity $(1835 \mathrm{U} / \mathrm{mL})$ was achieved in trial number 11 as a factorial point. This variation validates the CCD, in which different concentrations with different interactions result in different response values.

Multiple regression analysis and ANOVA. Tests for significance of the regression model, significance of individual model coefficients and lack-of-fit were conducted. The ANOVA results, which are summarized in Tables 4 and 5, demonstrated that both models were highly appropriate and adequate as was evident from model $F$-value (79.0 and 111.69 for NAP and NAR, respectively) with very low probability value $(0.000)$ for both. In addition, the multiple regression analysis explained the role of each individual variable, squared and their second-order interactions on NAP and NAR activities; based on signs (positive or negative effect on the response) and statistical significance of the coefficients $(P<0.05)$. Apparently, the probability values of the coefficients suggested that all linear and quadratic effects of the examined variables were more predominant terms for improving NAP activity than interaction effect. Moreover, the interaction effect of all variables appeared to be significant, with the exception of the interaction between $\mathrm{pH} \& \mathrm{Na}_{2} \mathrm{MoO}_{4} \cdot 2 \mathrm{H}_{2} \mathrm{O}, \mathrm{pH} \&$ sodium citrate and $\mathrm{Na}_{2} \mathrm{MoO}_{4} \cdot 2 \mathrm{H}_{2} \mathrm{O}$ \& inoculum size (\%).

However, it could be seen from the degree of significance that the linear effects of $\mathrm{pH}$, sodium-citrate and $\mathrm{NaNO}_{3}$ and quadratic effects of all variables were significant; meaning that they can act as limiting factors for NAR activity, and little changes in their values will alter the activity rate. Interactions between two factors could be described as an antagonistic effect (negative coefficient) such as the interaction between $\mathrm{pH}$ and sodium citrate. While, the interaction between sodium citrate and $\mathrm{NaNO}_{3}$ had a synergistic effect (positive coefficient), pointing out that increasing the concentration of both carbon/electron donor source and N/electron acceptor source can lead to enhance NAR activity.

The goodness of fit of the model was checked by calculating the determination coefficient $\mathrm{R}^{2}$, which was found to be 0.993 and 0.995 for NAP and NAR respectively, implying that 99.3 and $99.5 \%$ of the experimental data of the enzyme activity are compatible with the data predicted by the model, whereas only $0.7 \%$ and $0.5 \%$ of the total variations are not explained by the model. Besides, the values obtained for adj- $\mathrm{R}^{2}$ were 0.981 and 0.986 for NAP and NAR, respectively, indicating good adjustment and reasonable agreement with $\mathrm{R}^{2}$ value, thereby confirming high significance and the adequacy of the models.

Furthermore, lack of fit test was also performed. It describes the variation in the data around the fitted model ${ }^{30}$. The insignificant lack-of-fit is desired. It indicates that there might be contributions to the regresses-response relationship that are not accounted for by the model, and hence, a good model will have an insignificant lack-of-fit. The results of the lack of fit test, as inferred by ANOVA (Tables 4 and 5) were insignificant by 0.351 and 0.086 for NAP and NAR, respectively. Generally, results indicated that the models are good and well-fitted to the experimental data. The maximum NAP and NAR activities could be described as a function of the optimum levels of five independent variables. To evaluate the relationship between independent variables and response and to predict the maximum NAP and NAR activities corresponding to the optimum levels of significant variables, a second-order polynomial model (Eqs. 3 and 4 ) were proposed as follows:

$$
\begin{aligned}
\text { NAP activity }(\mathbf{U} / \mathbf{m L})= & 560+96.84 \mathrm{X} 1+135.16 \mathrm{X} 2+132.09 \mathrm{X} 3+51.93 \mathrm{X} 4 \\
& -16.03 \mathrm{X} 5+79.94(\mathrm{X} 1)^{2}+58.01(\mathrm{X} 2)^{2}+42.49(\mathrm{X} 3)^{2} \\
& +66.31(\mathrm{X} 4)^{2}+54.44(\mathrm{X} 5)^{2}+80.19 \mathrm{X} 1 * \mathrm{X} 2-57.38 \mathrm{X} 1 * \mathrm{X} 3 \% \\
& -12.60 \mathrm{X} 1 * \mathrm{X} 4+11.99 \mathrm{X} 1 * \mathrm{X} 5-38.02 \mathrm{X} 2 * \mathrm{X} 3+53.9 \mathrm{X} 2 * \mathrm{X} 4 \\
& +27.45 \mathrm{X} 2 * \mathrm{X} 5+7.64 \mathrm{X} 3 * \mathrm{X} 4+21.60 \mathrm{X} 3 * \mathrm{X} 5-42.50 \mathrm{X} 4 * \mathrm{X} 5
\end{aligned}
$$




\begin{tabular}{|c|c|c|c|c|c|c|c|c|c|c|c|c|}
\hline \multirow[b]{4}{*}{$\begin{array}{l}\text { Run } \\
\text { Order }\end{array}$} & \multicolumn{6}{|c|}{ NAP- CCD matrix } & \multirow[b]{4}{*}{$\begin{array}{l}\text { Actual NAP } \\
\text { Activity }(\mathrm{U} / \mathrm{mL})\end{array}$} & \multirow{4}{*}{$\begin{array}{l}\text { Predicted } \\
\text { NAP Activity } \\
\text { (U/mL) }\end{array}$} & \multirow[b]{4}{*}{ St. Residual } & \multirow[b]{4}{*}{$\begin{array}{l}\text { Actual NAR } \\
\text { Activity }(\mathrm{U} / \mathrm{mL})\end{array}$} & \multirow{4}{*}{$\begin{array}{l}\text { Predicted } \\
\text { NAR Activity } \\
\text { (U/mL) }\end{array}$} & \multirow[b]{4}{*}{$\begin{array}{l}\text { St. } \\
\text { Residual }\end{array}$} \\
\hline & $\begin{array}{l}(\mathrm{X} 1) \\
\mathrm{pH}\end{array}$ & \begin{tabular}{|l}
$(\mathrm{X} 2)$ \\
$\mathrm{FeCl}_{2} \cdot 4 \mathrm{H}_{2} \mathrm{O}$ \\
\end{tabular} & (X3) Inoculum S & size \% & $\begin{array}{l}(\mathrm{X} 4) \mathrm{Na}_{2} \mathrm{MoO}_{4} . \\
2 \mathrm{H}_{2} \mathrm{O}\end{array}$ & \begin{tabular}{|l|} 
(X5) \\
$\begin{array}{l}\text { Sodium } \\
\text { citrate }\end{array}$ \\
\end{tabular} & & & & & & \\
\hline & \multicolumn{6}{|c|}{ NAR-CCD matrix } & & & & & & \\
\hline & \begin{tabular}{|l|}
$\mathrm{X} 1)$ \\
$\mathrm{pH}$ \\
\end{tabular} & \begin{tabular}{|l|}
$(\mathrm{X} 2)$ \\
$\mathrm{FeCl}_{2} \cdot 4 \mathrm{H}_{2} \mathrm{O}$
\end{tabular} & $\begin{array}{l}(\mathrm{X} 3) \mathrm{Na}_{2} \mathrm{MoO}_{4} . \\
2 \mathrm{H}_{2} \mathrm{O}\end{array}$ & \multicolumn{2}{|c|}{ (X4) Sodium citrate } & $\begin{array}{l}\text { (X5) } \\
\mathrm{NaNO}_{3}\end{array}$ & & & & & & \\
\hline 1 & 0 & 2 & 0 & & 0 & 0 & 1059.29 & 1063.131 & -0.18 & 1421.0 & 1396.8 & 0.65 \\
\hline 2 & -1 & 1 & -1 & & -1 & -1 & 519.29 & 537.477 & -1.52 & 819.3 & 855.8 & -1.78 \\
\hline 3 & -1 & -1 & -1 & & -1 & 1 & 428.57 & 445.102 & -1.39 & 830.7 & 830.2 & 0.02 \\
\hline 4 & 1 & 1 & 1 & & -1 & -1 & 1022.14 & 1022.416 & -0.02 & 748.3 & 728.5 & 0.96 \\
\hline 5 & 1 & 1 & -1 & & 1 & -1 & 1282.14 & \begin{tabular}{|l|}
1263.797 \\
\end{tabular} & 1.54 & 386.6 & 400.4 & -0.67 \\
\hline 6 & -1 & 1 & -1 & & 1 & 1 & 717.29 & 714.763 & 0.21 & 1666.0 & 1690.1 & -1.17 \\
\hline 7 & 0 & -2 & 0 & & 0 & 0 & 525 & 522.478 & 0.12 & 1338.0 & 1393.5 & -1.49 \\
\hline 8 & 0 & 0 & 0 & & 2 & 0 & 894.29 & 929.885 & -1.64 & 276.0 & 282.4 & -0.17 \\
\hline 9 & 1 & -1 & -1 & & 1 & 1 & 532.86 & 512.862 & 1.68 & 469.0 & 445.8 & 1.13 \\
\hline 10 & 0 & 0 & 0 & & 0 & 0 & 602.86 & 560.743 & 1.34 & 406.7 & 371.1 & 0.66 \\
\hline 11 & -1 & -1 & 1 & & 1 & 1 & 879.29 & 879.506 & -0.02 & 1835.2 & 1810.4 & 1.21 \\
\hline 12 & 0 & 0 & -2 & & 0 & 0 & 463.57 & 466.533 & -0.14 & 558.2 & 515.9 & 1.13 \\
\hline 13 & 0 & 0 & 0 & & 0 & 0 & 533.57 & 560.743 & -0.86 & 306.7 & 371.1 & -1.19 \\
\hline 14 & 0 & 0 & 0 & & -2 & 0 & 756.43 & 722.155 & 1.58 & 133.2 & 158.1 & -0.67 \\
\hline 15 & -1 & -1 & 1 & & -1 & -1 & 889.86 & 910.789 & -1.75 & 1698.8 & 1686.4 & 0.6 \\
\hline 16 & 1 & 1 & -1 & & -1 & 1 & 1100.29 & 1096.168 & 0.35 & 998.5 & 990.6 & 0.38 \\
\hline 17 & 0 & 0 & 2 & & 0 & 0 & 996.57 & 994.926 & 0.08 & 487.1 & 560.8 & -1.97 \\
\hline 18 & -2 & 0 & 0 & & 0 & 0 & 724.29 & 686.825 & 1.73 & 1595.0 & 1556.0 & 1.05 \\
\hline 19 & 1 & -1 & 1 & & 1 & -1 & 917.23 & 901.629 & 1.31 & 515.2 & 480.1 & 1.71 \\
\hline 20 & -1 & 1 & 1 & & 1 & -1 & 1117.29 & 1119.161 & -0.16 & 594.0 & 606.1 & -0.59 \\
\hline 21 & 2 & 0 & 0 & & 0 & 0 & 1035.43 & \begin{tabular}{|l|l|}
1074.215 \\
\end{tabular} & -1.79 & 393.4 & 463.7 & -1.88 \\
\hline 22 & 0 & 0 & 0 & & 0 & 2 & 739.29 & 746.441 & -0.33 & 309.3 & 359.1 & -1.34 \\
\hline 23 & -1 & -1 & -1 & & 1 & -1 & 602.86 & 605.17 & -0.19 & 387.0 & 408.3 & -1.04 \\
\hline 24 & 0 & 0 & 0 & & 0 & 0 & 558.23 & 560.743 & -0.08 & 400.0 & 371.1 & 0.53 \\
\hline 25 & 1 & -1 & 1 & & -1 & 1 & 897.14 & 895.761 & 0.12 & 100.1 & 43.3 & 2.77 \\
\hline 26 & 0 & 0 & 0 & & 0 & 0 & 561.6 & 560.743 & 0.03 & 389.9 & 371.1 & 0.35 \\
\hline 27 & 0 & 0 & 0 & & 0 & -2 & 816.43 & 810.598 & 0.27 & 105.0 & 86.4 & 0.5 \\
\hline 28 & 1 & -1 & -1 & & -1 & -1 & 662.86 & 663.575 & -0.06 & 330.0 & 319.3 & 0.52 \\
\hline 29 & 0 & 0 & 0 & & 0 & 0 & 522.14 & 560.743 & -1.23 & 361.9 & 371.1 & -0.17 \\
\hline 30 & 1 & 1 & 1 & & 1 & 1 & 1334.71 & \begin{tabular}{|l|}
1314.273 \\
\end{tabular} & 1.71 & 470.0 & 437.7 & 1.57 \\
\hline 31 & -1 & 1 & 1 & & -1 & 1 & 892.86 & 908.953 & -1.35 & 337.2 & 327.6 & 0.47 \\
\hline 32 & 0 & 0 & 0 & & 0 & 0 & 587.38 & 560.743 & 0.85 & 393.0 & 371.1 & 0.4 \\
\hline \multirow{2}{*}{\multicolumn{8}{|c|}{ Variable }} & \multicolumn{5}{|c|}{ Coded levels/Experimental Values } \\
\hline & & & & & & & & -2 & -1 & 0 & 1 & 2 \\
\hline \multicolumn{8}{|l|}{$\mathrm{pH}$} & 5.8 & 6.3 & 6.8 & 7.3 & 7.8 \\
\hline \multicolumn{8}{|c|}{ Inoculum Size (0.5 McFarland) (\%) } & 2.5 & 4 & 5 & 7.5 & 10 \\
\hline \multicolumn{8}{|c|}{$\mathrm{NaNO}_{3}(\mathrm{~g} / \mathrm{L})$} & 4 & 5.5 & 7 & 8.5 & 10 \\
\hline \multicolumn{8}{|c|}{$\mathrm{FeCl}_{2} \cdot 4 \mathrm{H}_{2} \mathrm{O}(\mathrm{mg} / \mathrm{L})$} & 300 & 350 & 400 & 450 & 500 \\
\hline \multicolumn{8}{|c|}{$\mathrm{Na}_{2} \mathrm{MoO}_{4} \cdot 2 \mathrm{H}_{2} \mathrm{O}(\mathrm{mg} / \mathrm{L})$} & 30 & 70 & 100 & 150 & 200 \\
\hline \multicolumn{8}{|c|}{ Sodium citrate $(\mathrm{g} / \mathrm{L})$} & 4 & 5.5 & 7 & 8.5 & 10 \\
\hline
\end{tabular}

Table 3. Central composite design matrix, representing the response of NAP and NAR activities as influenced by significant factors along with the predicted activity, residuals and concentrations of variables levels.

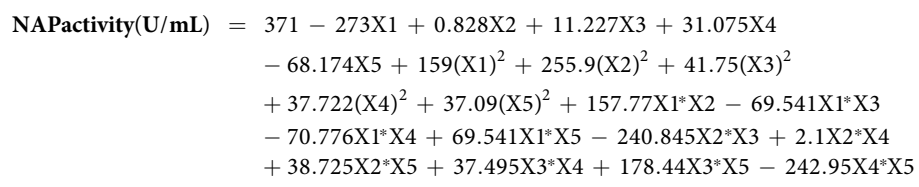




\begin{tabular}{|c|c|c|c|c|c|c|}
\hline Term & Coef & SE Coef & $\mathrm{T}$ & $P$ & & \\
\hline Constant & 560.743 & 13.669 & 41.022 & 0.000 & & \\
\hline $\mathrm{X} 1$ & 96.848 & 6.996 & 13.844 & 0.000 & & \\
\hline $\mathrm{X} 2$ & 135.163 & 6.996 & 19.321 & 0.000 & & \\
\hline $\mathrm{X} 3$ & 132.098 & 6.996 & 18.883 & 0.000 & & \\
\hline $\mathrm{X} 4$ & 51.933 & 6.996 & 7.424 & 0.000 & & \\
\hline $\mathrm{X} 5$ & -16.039 & 6.996 & -2.293 & 0.043 & & \\
\hline$(\mathrm{X} 1)^{2}$ & 79.944 & 6.328 & 12.634 & 0.000 & & \\
\hline$(\mathrm{X} 2)^{2}$ & 58.015 & 6.328 & 9.168 & 0.000 & & \\
\hline$(\mathrm{X} 3)^{2}$ & 42.497 & 6.328 & 6.716 & 0.000 & & \\
\hline$(X 4)^{2}$ & 66.319 & 6.328 & 10.481 & 0.000 & & \\
\hline$(\mathrm{X} 5)^{2}$ & 54.444 & 6.328 & 8.604 & 0.000 & & \\
\hline $\mathrm{X} 1 * \mathrm{X} 2$ & 80.19 & 8.568 & 9.359 & 0.000 & & \\
\hline $\mathrm{X} 1 * \mathrm{X} 3$ & -57.389 & 8.568 & -6.698 & 0.000 & & \\
\hline $\mathrm{X} 1 * \mathrm{X} 4$ & -12.602 & 8.568 & -1.471 & 0.169 & & \\
\hline X1 X5 & 11.995 & 8.568 & 1.4 & 0.189 & & \\
\hline $\mathrm{X} 2 * \mathrm{X} 3$ & -38.024 & 8.568 & -4.438 & 0.001 & & \\
\hline $\mathrm{X} 2 * \mathrm{X} 4$ & 53.94 & 8.568 & 6.296 & 0.000 & & \\
\hline $\mathrm{X} 2 * \mathrm{X} 5$ & 27.453 & 8.568 & 3.204 & 0.008 & & \\
\hline $\mathrm{X} 3 * \mathrm{X} 4$ & 7.649 & 8.568 & 0.893 & 0.391 & & \\
\hline $\mathrm{X} 3 * \mathrm{X} 5$ & 21.601 & 8.568 & 2.521 & 0.028 & & \\
\hline $\mathrm{X} 4 * \mathrm{X} 5$ & -42.505 & 8.568 & -4.961 & 0.000 & & \\
\hline Source & Df & Seq SS & Adj SS & Adj MS & $F$ & $P$ \\
\hline Regression & 20 & 1856884 & 1856884 & 92844 & 79.05 & 0.000 \\
\hline Linear & 5 & 1153267 & 1153267 & 230653 & 196.38 & 0.000 \\
\hline Square & 5 & 424140 & 424140 & 84828 & 72.22 & 0.000 \\
\hline Interaction & 10 & 279478 & 279478 & 27948 & 23.8 & 0.000 \\
\hline Residual Error & 11 & 12920 & 12920 & 1175 & & \\
\hline Lack of fit & 6 & 8201 & 8201 & 1367 & 1.45 & 0.351 \\
\hline Pure error & 5 & 4719 & 4719 & 944 & & \\
\hline Total & 31 & 1869804 & & & & \\
\hline
\end{tabular}

Table 4. Estimated effect, regression coefficients and corresponding $T$ and $P$ values in addition to ANOVA analysis for the optimization of NAP activity using central composite design (CCD).

Graphical interpretation of the response surface model. The three-dimensional response surface plot and twodimensional contour plots are graphical representation of the model equations obtained in the regression analysis to figure out the interaction of the studied variables and the optimal levels of each variable predicted for the optimal NAP/NAR activity ${ }^{31}$. The empirical functional relationship is expressed as the response on the vertical axis and coded levels of two explanatory factors on horizontal axes, while the remaining factors are held at the center point (zero levels) (Fig. 1A-H). There was common manner exhibited by surface plots of both NAP and NAR. As noticed, the plot was a U-shaped parabola, which opened upward and had the stationary point directed to be minimum.

Figure $1(\mathrm{~A}, \mathrm{~B})$ represents a $2 \mathrm{D}$-contour plot and $3 \mathrm{D}$-surface plot as a function of $\mathrm{FeCl}_{2} \cdot 4 \mathrm{H}_{2} \mathrm{O}$ and $\mathrm{Na}_{2} \mathrm{MoO}_{4} \cdot 2 \mathrm{H}_{2} \mathrm{O}$ on NAP activity at a constant values of sodium citrate, $\mathrm{pH}$ and inoculum size (\%) at their zero levels. It showed that when concentrations of $\mathrm{FeCl}_{2} \cdot 4 \mathrm{H}_{2} \mathrm{O}$ and $\mathrm{Na}_{2} \mathrm{MoO}_{4} \cdot 2 \mathrm{H}_{2} \mathrm{O}$ increased, the NAP activity gradually increased. The elliptical contour plot (Fig. 1A) confirmed the significant synergistic interaction between two factors. Broadly, the shape of the contour plot points out the nature and extent of the interactions between the variables. Elliptical and saddle-shaped contour plots elucidate a significant interaction between variables, whereas, a circular contour plot reveals an insignificant interaction between variables ${ }^{25}$. As a consequence, the correlation between $\mathrm{Na}_{2} \mathrm{MoO}_{4} \cdot 2 \mathrm{H}_{2} \mathrm{O}$ and $\mathrm{pH}$ was considered to be insignificant (Fig. 2C). Maximum NAP activity could be achieved by increasing the concentration of $\mathrm{Na}_{2} \mathrm{MoO}_{4} \cdot 2 \mathrm{H}_{2} \mathrm{O}$ while decreasing $\mathrm{pH}$ value or vice versa, implying the antagonistic interaction (Fig. 2D).

Nonetheless, maximum NAR activity was clearly observed at a low $\mathrm{pH}$ value, which was associated with a low concentration of $\mathrm{FeCl}_{2} \cdot 4 \mathrm{H}_{2} \mathrm{O}$, reflecting a synergistic interaction between them (Fig. 1E,F). On the other hand, a ridged surface plot and a saddle-like stationary point was observed for the response, reflecting an antagonistic effect of the interaction between $\mathrm{Na}_{2} \mathrm{MoO}_{4} \cdot 2 \mathrm{H}_{2} \mathrm{O}$ and $\mathrm{NaNO}_{3}$ on NAR activity, as shown in Fig. 1G,H. NAR activity increased with increasing $\mathrm{Na}_{2} \mathrm{MoO}_{4} \cdot 2 \mathrm{H}_{2} \mathrm{O}$ and decreasing in $\mathrm{NaNO}_{3}$ concentration or vice versa. From the corresponding contour plot, a significant interaction was observed between $\mathrm{Na}_{2} \mathrm{MoO}_{4} \cdot 2 \mathrm{H}_{2} \mathrm{O}$ and $\mathrm{NaNO}_{3}$.

The reduced regression model was solved for predicting the maximum NAP/NAR activity using the Response Optimizer tool in MINITAB 14.0. Minitab's Response Optimizer calculates individual desirability using a desirability function (also called utility transfer function). The predicted optimal levels of the process variables for NAP activity of strain $10 \mathrm{~B}$ were as follows: $\mathrm{pH}, 7.8 ; \mathrm{Na}_{2} \mathrm{MoO}_{4} \cdot 2 \mathrm{H}_{2} \mathrm{O}, 200 \mathrm{mg} / \mathrm{L} ; \mathrm{FeCl}_{2} \cdot 4 \mathrm{H}_{2} \mathrm{O}, 500 \mathrm{mg} / \mathrm{L}$; sodium citrate, 


\begin{tabular}{|c|c|c|c|c|c|c|}
\hline Term & Coef & SE Coef & T & $P$ & & \\
\hline Constant & \begin{tabular}{|l|}
371.148 \\
\end{tabular} & 23.5 & 15.793 & 0.000 & & \\
\hline $\mathrm{X} 1$ & -273.068 & 12.03 & -22.704 & 0.000 & & \\
\hline $\mathrm{X} 2$ & 0.828 & 12.03 & 0.069 & 0.946 & & \\
\hline $\mathrm{X} 3$ & 11.227 & 12.03 & 0.933 & 0.371 & & \\
\hline $\mathrm{X} 4$ & 31.075 & 12.03 & 2.584 & 0.025 & & \\
\hline X5 & 68.174 & 12.03 & 5.668 & 0.000 & & \\
\hline$(\mathrm{X} 1)^{2}$ & 159.67 & 10.88 & 14.677 & 0.000 & & \\
\hline$(\mathrm{X} 2)^{2}$ & 255.998 & 10.88 & 23.532 & 0.000 & & \\
\hline$(\mathrm{X} 3)^{2}$ & 41.795 & \begin{tabular}{|l|}
10.88 \\
\end{tabular} & 3.842 & 0.003 & & \\
\hline$(\mathrm{X} 4)^{2}$ & -37.722 & 10.88 & -3.467 & 0.005 & & \\
\hline$(\mathrm{X} 5)^{2}$ & -37.09 & 10.88 & -3.409 & 0.006 & & \\
\hline $\mathrm{X} 1 * \mathrm{X} 2$ & 157.773 & 14.73 & 10.711 & 0.000 & & \\
\hline $\mathrm{X} 1 * \mathrm{X} 3$ & -69.544 & 14.73 & -4.721 & 0.001 & & \\
\hline $\mathrm{X} 1 * \mathrm{X} 4$ & -70.776 & 14.73 & -4.805 & 0.001 & & \\
\hline $\mathrm{X} 1 * \mathrm{X} 5$ & -69.541 & 14.73 & -4.721 & 0.001 & & \\
\hline $\mathrm{X} 2 * \mathrm{X} 3$ & -240.845 & 14.73 & -16.35 & 0.000 & & \\
\hline $\mathrm{X} 2 * \mathrm{X} 4$ & -2.1 & 14.73 & -0.143 & 0.889 & & \\
\hline $\mathrm{X} 2 * \mathrm{X} 5$ & 38.725 & 14.73 & 2.629 & 0.023 & & \\
\hline $\mathrm{X} 3 * \mathrm{X} 4$ & 37.495 & 14.73 & 2.545 & 0.027 & & \\
\hline $\mathrm{X} 3 * \mathrm{X} 5$ & -178.44 & 14.73 & -12.114 & 0.000 & & \\
\hline $\mathrm{X} 4 * \mathrm{X} 5$ & 242.957 & 14.73 & 16.494 & 0.000 & & \\
\hline Source & DF & Seq SS & Adj SS & Adj MS & $F$ & $P$ \\
\hline Regression & 20 & 7754656 & 7754656 & 387733 & 111.69 & 0.000 \\
\hline Linear & 5 & 1927351 & 1927351 & 385470 & 111.03 & 0.000 \\
\hline Square & 5 & 2765558 & 2765558 & 553112 & 159.32 & 0.000 \\
\hline Interaction & 10 & 3061748 & 3061748 & 306175 & 88.19 & 0.000 \\
\hline Residual Error & 11 & 38188 & 38188 & 3472 & & \\
\hline Lack of fit & 6 & 31186 & 31186 & 5198 & 3.71 & 0.086 \\
\hline Pure error & 5 & 7002 & 7002 & 1400 & & \\
\hline Total & 31 & \begin{tabular}{|l|l|}
7792845 \\
\end{tabular} & & & & \\
\hline
\end{tabular}

Table 5. Estimated effect, regression coefficients and corresponding $T$ and $P$ values in addition to ANOVA analysis for the optimization of NAR activity using central composite design (CCD).

$4 \mathrm{~g} / \mathrm{L}$; and inoculum size, $0.5 \mathrm{McFarland} 2.5 \%$. On the other hand, for NAR activity, the following optimal values recorded: $\mathrm{pH}, 5.8 ; \mathrm{NaNO}_{3}, 10 \mathrm{~g} / \mathrm{L}$; sodium- citrate, $10 \mathrm{~g} / \mathrm{L} ; \mathrm{Na}_{2} \mathrm{MoO}_{4} \cdot 2 \mathrm{H}_{2} \mathrm{O}, 200 \mathrm{mg} / \mathrm{L} ;$ and $\mathrm{FeCl}_{2} \cdot 4 \mathrm{H}_{2} \mathrm{O}, 300 \mathrm{mg} / \mathrm{L}$.

Experimental verification of model. In order to determine the accuracy of both models and to verify the results, using the optimized conditions suggested by CCD, an experiment was carried out in triplicate and in parallel with basal media before optimization process. The optimization strategy led to a 2.14-fold enhancement of NAP activity from $1161 / \mathrm{mL}$ to $2490 \mathrm{U} / \mathrm{mL}$. While, NAR activity was $1522 \mathrm{U} / \mathrm{mL}$ under basal conditions, and improved to $3050 \mathrm{U} / \mathrm{mL}$ by 2 -fold increase under optimized conditions.

It is noteworthy that molybdenum cofactor (Mo-co) and cytochrome subunits (haem or iron-sulphur clusters [4Fe-4S]) are incorporated in the NAP/NAR active center in the catalytic subunit ${ }^{32}$. Moreover, iron has the vital role in iron-rich electron transfer systems (ETS), which are essential for ATP synthesis in aerobic heterotrophic bacteria, as referred by Kirchman et al. ${ }^{33}$. This result is in agreement with the finding of Eltarahony et al. ${ }^{34}$ who highlighted the importance of molybdenum and iron for NAP of Achromobacter sp. MMT. It should be noted that sodium citrate is widely used as a carbon/electron source for anaerobic denitrification process ${ }^{35,36}$. It is clear that electrons generated from carbon substrate metabolism are conserved for $\mathrm{NO}_{3}{ }^{-}$reduction and subsequently drive energy generation. As reported by Gamez et al..$^{37}$ and $\mathrm{Li}$ et $a l .{ }^{38}$, the metabolic pathway used for citrate utilization under anaerobic conditions varied from that used aerobically (i.e., the TCA cycle). In general, three different fermentation pathways have been described in enterobacteria for anaerobic utilization of citrate. Actually, it is converted to several products, such as acetate, propionate, formate, pyruvate and succinate ended by $\mathrm{CO}_{2}$, all of which participate in the electron donating cycle.

In fact, the statistical design was substantially successful at finding an equilibration between cell density (2.5\%) and substrate concentration $(4 \mathrm{~g} / \mathrm{L})$ to maximize NAP activity. In contrast, nitrate reduction by strain Zoogloea N299 showed no significant difference among the tested inoculums dosages $(2-10 \%)^{36}$. Whereas, increasing the initial cell count of M. roseus and E. coli O157:H7 elevated nitrate reduction rate after $24 \mathrm{hr}$. of incubation ${ }^{39}$.

Apparently, NAP and NAR activities of strain 10B seemed to be $\mathrm{pH}$ dependent but differently. As reported in several previous studies, the most adequate $\mathrm{pH}$ for nitrate reduction always ranged from the neutral to slightly alkaline conditions (6.5-7.8), which is in concordance with our results for NAP enzyme ${ }^{34,40}$. On the other hand, the maximum NAR activity was predicted under initial acidic conditions (5.8). That could be explained by the 

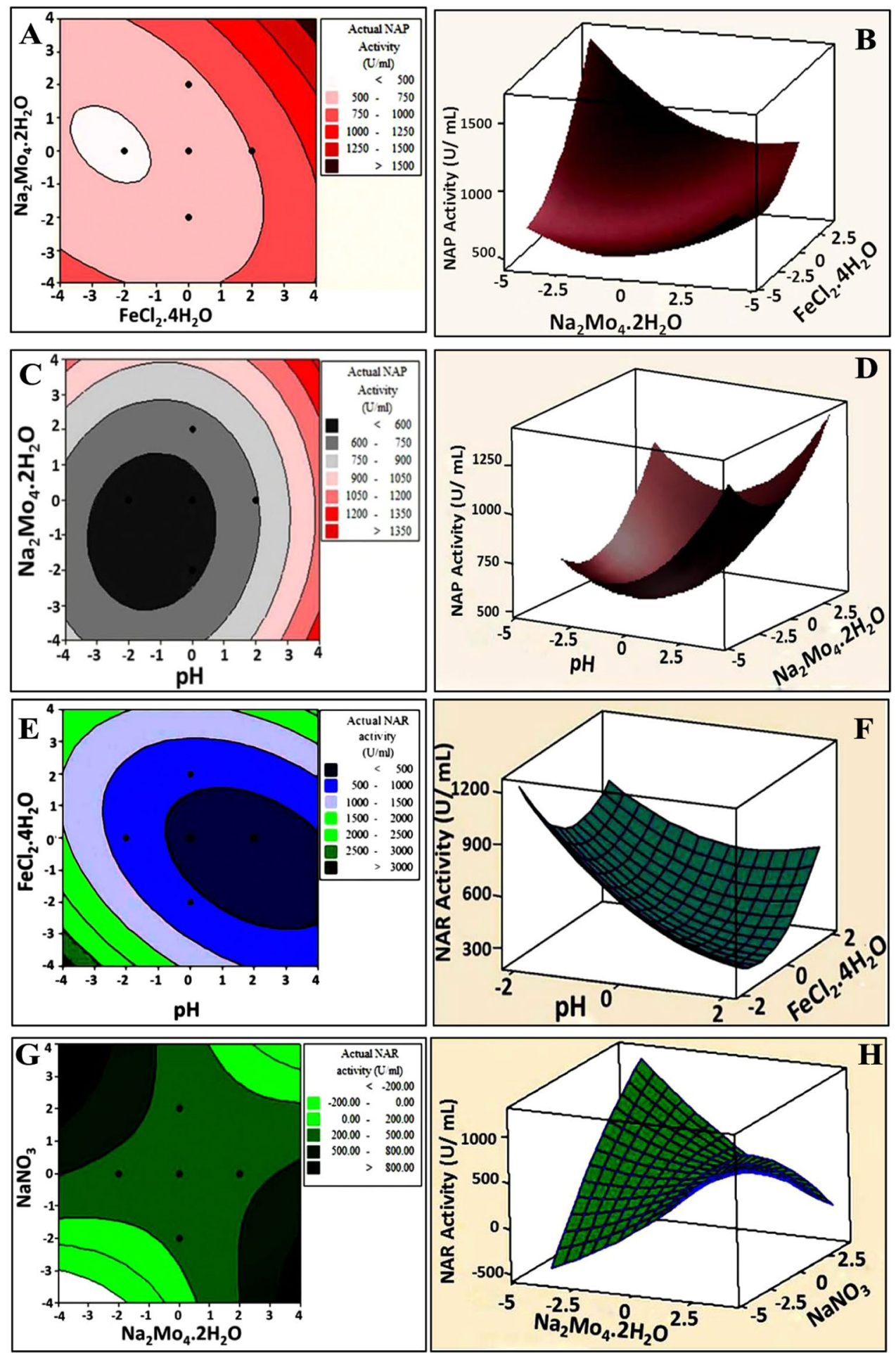

Figure 1. 2D-Contour plot (left panels) and 3D-Surface plot (right panels) showing the interactive effects of independent significant variables on NAP activity (A-D) and NAR activity (E-H).

generation of some byproducts such as oxygen hydroxide $\left(\mathrm{OH}^{-}\right)$along with carbon dioxide $\left(\mathrm{CO}_{2}^{-}\right)$, which were formed from the anaerobic reduction of nitrate concurrently with citrate utilization. The interaction of these products generates bicarbonate $\mathrm{HCO}_{3}{ }^{-}$and carbonates $\mathrm{CO}_{3}{ }^{2-}$ and may induce a certain amount of alkalinity, which donates buffering capacity as suggested by Drtil et al. ${ }^{41}$. Consistent with our results, Aoki et al. ${ }^{42}$ documented that Micrococcus denitrifican and M. halodenitrificans that were isolated from rice field soil had optimum $\mathrm{pH}$ at 5.6 and 6.3, respectively, for nitrate removal. Notably, under aerobic conditions, facultative anaerobes, which are capable of performing denitrification, prefer oxygen to nitrate as electron acceptor as oxygen has a 


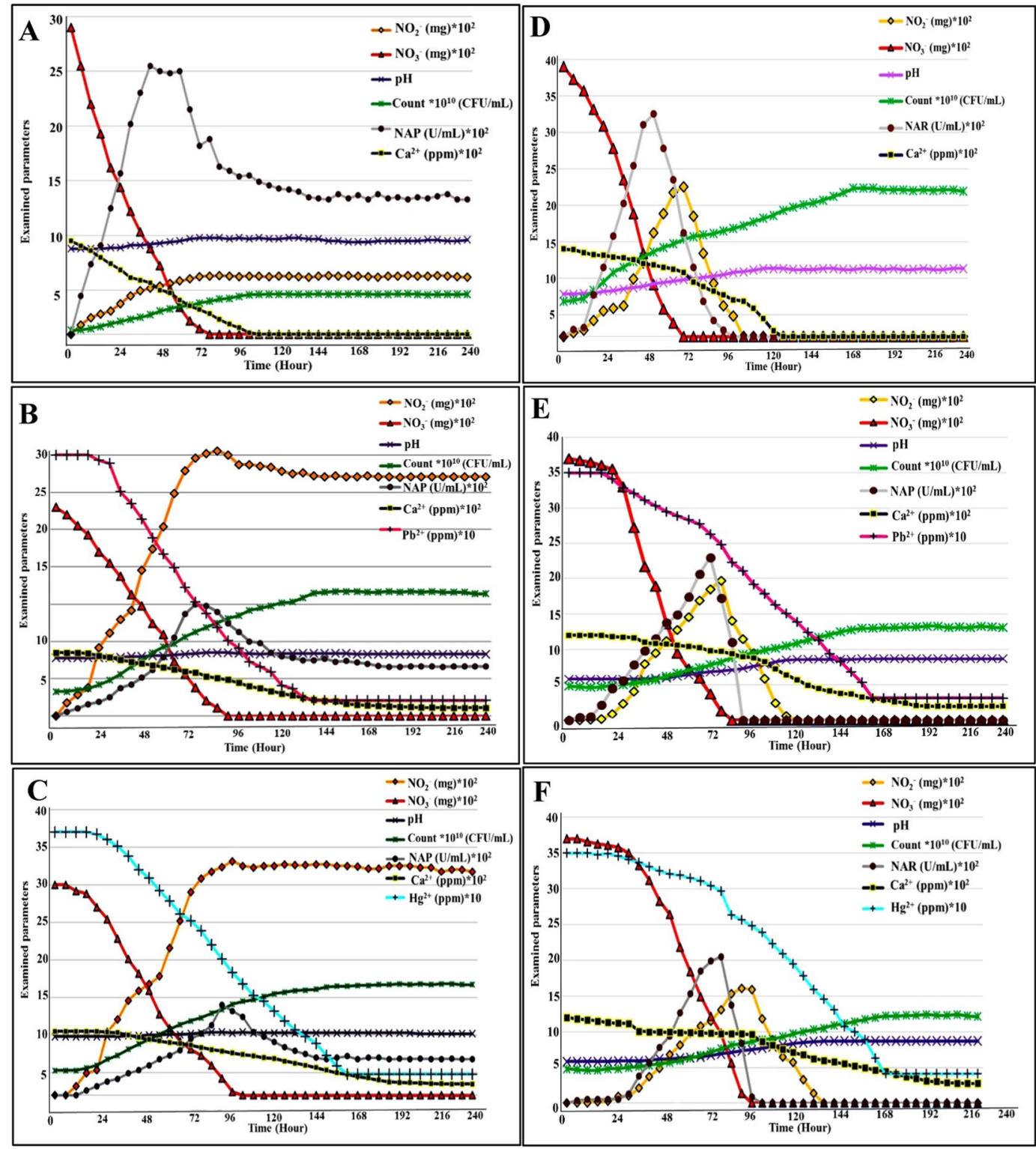

Figure 2. Bioremediation process of $\mathrm{Pb}^{2+}$ and $\mathrm{Hg}^{2+}$ through aerobic and anaerobic nitrate utilization and study of the changes in media chemistry during MICP. (A) Aerobic biotic control; (B) Aerobic remediation of $\mathrm{Pb}^{2+}$; (C) Aerobic remediation of $\mathrm{Hg}^{2+}$; (D) Anaerobic biotic control; (E) Anaerobic remediation of $\mathrm{Pb}^{2+}$ and (F) Anaerobic remediation of $\mathrm{Hg}^{2+}$. The average of three replica were performed for each one. To adjust the scale, the parameters are multiplied in factor as indicated on the figures.

higher redox potential $(+818 \mathrm{mV})$ than nitrate $(420 \mathrm{mV})^{43}$. Hence, nitrate was not a critical parameter to improve NAP activity in this study.

Bioremediation of $\mathrm{Pb}^{2+}$ and $\mathrm{Hg}^{2+}$ in MICCP process. The ability of strain $10 \mathrm{~B}$ to precipitate $\mathrm{Pb}^{2+}$ and $\mathrm{Hg}^{2+}$ via nitrate dissimilation under oxic/anoxic conditions and the changes in media chemistry were monitored. This was performed through assessment of some parameters as a function of time for experimental trials, biotic (without metals) and abiotic (without bacteria) controls. Broadly, there was a positive correlation between bacterial growth and NAP/NAR activity which were synchronized with $\mathrm{pH}$ elevation, removal of soluble $\left(\mathrm{Ca}^{2+}, \mathrm{Pb}^{2+}\right.$ and $\mathrm{Hg}^{2+}$ ) and $\mathrm{NO}_{3}{ }^{-} / \mathrm{NO}_{2}{ }^{-}$reduction as deduced from Fig. (2). In the biotic control, the growth profile of strain 10B exhibited a typical growth stages (lag, logarithmic and stationary) aerobically and anaerobically. As depicts in Fig. 2A, under aerobic conditions, the cell number in biotic control increased rapidly and exhibited maximum NAP activity at $48 \mathrm{hr}$. by $2450 \mathrm{U} / \mathrm{mL}$ with cell density assessed by $17.6 \times 10^{8} \mathrm{CFU} / \mathrm{mL}$. Besides, the measured $\mathrm{pH}$ increased consistently during incubation from initial $\mathrm{pH} 7.8$ and recorded 8.7 by the end of the experiment. Additionally, a complete $\mathrm{NO}_{3}{ }^{-}$reduction was noticed at $84 \mathrm{hr}$. with accumulation of $\mathrm{NO}_{2}^{-}$. As initially presented in the optimized MICP media (aerobically), the soluble $\mathrm{Ca}^{2+}$ depletion by $98.4 \%$ (from $850 \mathrm{ppm}$ to $13.7 \mathrm{ppm}$ ) at $108 \mathrm{hr}$. provided an evidence on $\mathrm{CaCO}_{3}$ precipitation. 
On the other hand, the overall decrease in cell density and retardation of growth phases were observed in presence of $\mathrm{Pb}^{2+}$ and $\mathrm{Hg}^{2+}$. That could be possibly assigned to the acclimatization stage of bacteria upon being exposed to stress factor in culture media. In the same extent, Mwandira et al. ${ }^{44}$ noticed delay in log phase and noticeable decrease in the growth of Pararhodobacter sp. in presence of $\mathrm{Pb}^{2+}$. In the present study, the logarithmic phase began after 12 and $18 \mathrm{hr}$. for $\mathrm{Pb}^{2+}$ and $\mathrm{Hg}^{2+}$, respectively. The maximum NAP activity displayed by $11.3 \times 10^{8} \mathrm{CFU} / \mathrm{mL}$ and $11.4 \times 10^{8} \mathrm{CFU} / \mathrm{mL}$ were 1500 and $1200 \mathrm{U} / \mathrm{mL}$ in 78 and $96 \mathrm{hr}$. for $\mathrm{Pb}^{2+}$ and $\mathrm{Hg}^{2+}$, respectively (Fig. 2B,C). This implied the effect of both metals on overall bacterial cell performance including enzyme activity ${ }^{44}$. A gradual uplifting in $\mathrm{pH}$ was observed from 7.8 to 8.4 for both aerobically remediated metals. Furthermore, nitrate was totally reduced at 96 and $108 \mathrm{hr}$. for $\mathrm{Pb}^{2+}$ and $\mathrm{Hg}^{2+}$, correspondingly with accumulation of nitrite as noticed in the biotic control. Remarkably, effective removal percentage reached to $95.2 \%$ for $\mathrm{Pb}^{2+}$ and $92 \%$ for $\mathrm{Hg}^{2+}$ were displayed within 144 and $168 \mathrm{hr}$., respectively as inferred by ICP-OES analysis. Where, the remaining concentration of soluble $\mathrm{Pb}^{2+}$ and $\mathrm{Hg}^{2+}$ assessed 17 and $28 \mathrm{ppm}$, from initial concentration of $350 \mathrm{ppm}$ ( $1 / 2$ MIC of each heavy metal, data not shown). Further, by $240 \mathrm{hr}$. of incubation, the measured $\mathrm{Ca}^{2+}$ in aqueous media recorded 113 and $151 \mathrm{ppm}$, from initial concentration of $850 \mathrm{ppm}$, for $\mathrm{Pb}^{2+}$ and $\mathrm{Hg}^{2+}$, respectively, which is equivalent to 86.6 and $82.3 \%$ of its precipitation.

In comparison, the anaerobic cultures $\left(13.3 \times 10^{8}, 8.8 \times 10^{7}\right.$ and $\left.8.5 \times 10^{7} \mathrm{CFU} / \mathrm{mL}\right)$ of the biotic control, MICP cultures with $\mathrm{Pb}^{2+}$ and $\mathrm{Hg}^{2+}$ completely reduced $\mathrm{NO}_{3}{ }^{-}$by 72,90 and $108 \mathrm{hr}$., respectively. The maximum NAR activity evaluated by 3050,2300 and $2050 \mathrm{U} / \mathrm{mL}$ at 54,78 and $90 \mathrm{hr}$., for biotic control, $\mathrm{Pb}^{2+}$ and $\mathrm{Hg}^{2+}$ remediated cultures, respectively (Fig. 2D-F). However, the reduction of whole $\mathrm{NO}_{2}{ }^{-}$accomplished in 108,126 and $150 \mathrm{hr}$. as the previous order. In accompanying to the denitrification process, the elevation in $\mathrm{pH}$ was observed by 9.3 for biotic control and 8.9 for both remediated samples. Such increasing in $\mathrm{pH}$ contributed mainly in deposition of 1200, 1008 and 925 ppm of $\mathrm{Ca}^{2+}$ in the form of $\mathrm{CaCO}_{3}$ crystals with removal percentage evaluated by 100,84 and $77 \%$ for the biotic control, $\mathrm{Pb}^{2+}$ and $\mathrm{Hg}^{2+}$ remediated cultures, correspondingly. Despite the anoxic precipitation of $91.1 \%\left(\mathrm{~Pb}^{2+}\right)$ and $88.3 \%\left(\mathrm{Hg}^{2+}\right)$, correspond to 319 and $309 \mathrm{ppm}$ by 168 and $186 \mathrm{hr}$., respectively, it seemed to be slower and with slightly lower performance than aerobic bioremediation. That could be explained by higher redox potential under aerobic conditions as reported previously by Ilbert \& Bonnefoy ${ }^{43}$. That led to higher nitrate reduction, bacterial metabolic activity and proliferation, therefore availability of more nucleation sites and eventually faster bioremediation of soluble pollutants. Interestingly, no precipitation was found in the abiotic (chemical) control, reflecting the importance of bacterial activity for altering the physicochemical parameters of the culture media which consequently promoted $\mathrm{CaCO}_{3}$ precipitation. It is important to mention that the higher rate of metals removal was obviously occurred during log phase as reported by Kang et al. ${ }^{45}$, which concurred with our finding.

Apparently, the nitrate utilization process is the main mechanism that conducted metals precipitation in the current study. Notably, NAP enzyme played a crucial role in rapid utilization of $\mathrm{NO}_{3}{ }^{-}$in association to citrate breakdown and protons consumption. Such subsequently led to bicarbonate generation and $\mathrm{pH}$ increasing, which ultimately favors $\mathrm{CaCO}_{3}$ precipitation. As referred by Singh et al. ${ }^{46}$, the increasing in $\mathrm{pH}$ and alkalinity as a result

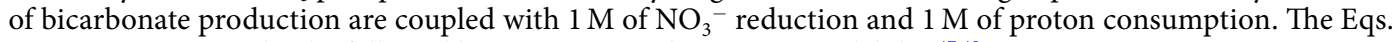
(5-7) were suggested to be followed by strain $10 \mathrm{~B}$ under oxygen availability ${ }^{47,48}$ :

$$
\begin{gathered}
3 \mathrm{C}_{6} \mathrm{H}_{6} \mathrm{O}_{7} \mathrm{Na}_{2}+ \\
\mathrm{CO}_{2}+\mathrm{H}_{2} \mathrm{O} \leftrightarrow \mathrm{HCO}_{3}^{-}+\mathrm{H}^{+} \ldots \ldots \ldots \\
\mathrm{HCO}_{3}{ }^{-}+\mathrm{Ca}^{2+} \leftrightarrow \mathrm{CaCO}_{3}+\mathrm{H}^{+} \ldots \ldots
\end{gathered}
$$

On the other hand, the following equation could recap the anaerobic denitrification mechanism for $\mathrm{CaCO}_{3}$ biodeposition ${ }^{23,49}$

$$
5 \mathrm{C}_{6} \mathrm{H}_{6} \mathrm{O}_{7} \mathrm{Na}_{2}+9 \mathrm{Ca}\left(\mathrm{NO}_{3}\right)_{2} \rightarrow 9 \mathrm{CaCo}_{3} \downarrow+9 \mathrm{~N}_{2} \uparrow+21 \mathrm{CO}_{2} \uparrow+10 \mathrm{H}_{2} \mathrm{O}+10 \mathrm{NaOH}
$$

where, strain 10B oxidized the carbon and electron donor (citrate) and reduced nitrate (electron acceptor) by NAR enzyme to drive energy and enhance cells for proliferation. Additionally, higher $\mathrm{pH}$ was recorded under oxygen limitation as a consequence of complete reduction of both $\mathrm{NO}_{3}{ }^{-}$and $\mathrm{NO}_{2}{ }^{-}$and simultaneous utilization of more protons. Singh et al. ${ }^{46}$ and O'Donnell et al. ${ }^{47}$, stated that the $\mathrm{NO}_{2}{ }^{-}$reduction is a decisive step in denitrification process. As more and continuous consumption of $\mathrm{H}^{+}$and higher yield of bicarbonate ions occurred at this stage. Evidently, the variance in physiological functions of both NAP and NAR led to differences in their expression along with MICP process. Where, NAP enzyme was actively expressed till the accomplishment of MICP, even after the complete depletion of $\mathrm{NO}_{3}{ }^{-}$and in the accumulation of $\mathrm{NO}_{2}{ }^{-}$. Where, it conserves redox balance by dissipating excess reductant during aerobic growth and scavenging toxic concentrations of nitrate and nitrite as documented by $\mathrm{Li}$ et al. ${ }^{50}$. However, NAR enzyme was induced only anaerobically in the presence of $\mathrm{NO}_{3}{ }^{-}$and its activity was stalled thereafter. Where, the main function is to produce electrochemical proton gradient and generation of ATP via nitrate respiration ${ }^{51}$. Therefore, nitrate reductases (NAP and NAR) serve as a good bioindicators in the MICP process and subsequently removal of $\mathrm{Pb}^{2+}$ and $\mathrm{Hg}^{2+}$.

Accordingly, under rising of $\mathrm{pH}$ and alkalinity in the culture media, the bio precipitation/crystallization process is commenced via two steps, including crystal nucleation and crystal growth. Actually, the bacterial cells themselves acting as nucleation sites by the virtue of their electronegativity nature. Where, the negative charges biomolecules such as peptidoglycans, teichoic acids, lipids and lipopolysaccharide contain functional groups such as carboxylic $\left(\mathrm{R}-\mathrm{COO}{ }^{-}\right)$, sulfonate $\left(\mathrm{R}-\mathrm{SO}_{3}{ }^{-}\right)$and phosphatic $\left(\mathrm{R}-\mathrm{PO}_{4}{ }^{2-}\right)$ attract positively charged ions by 


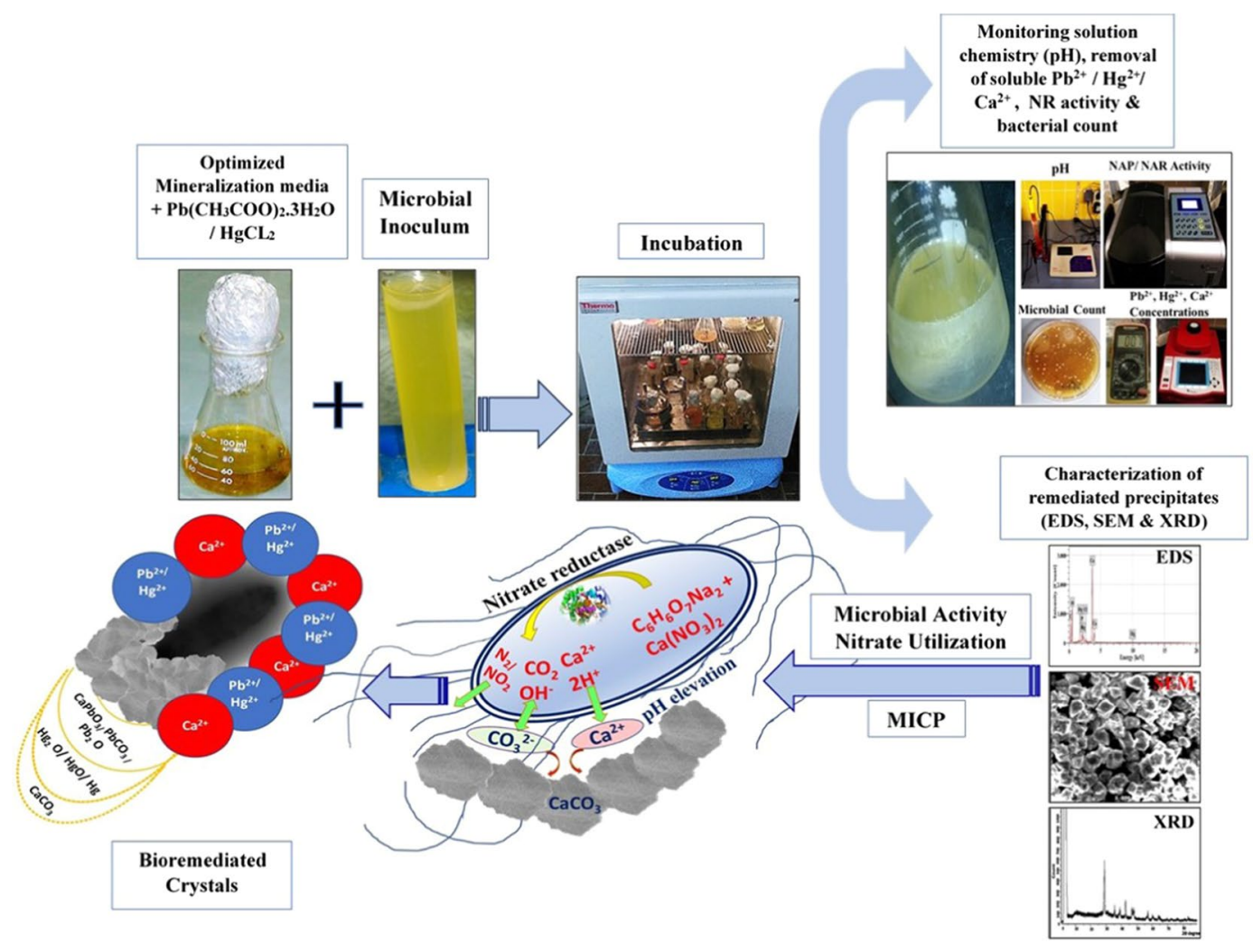

Figure 3. Schematic illustration of $\mathrm{Pb}^{2+}$ and $\mathrm{Hg}^{2+}$ bioremediation in MICP process through nitrate utilization strategy.

attractive van der Waals forces ${ }^{52}$. Thus, by generation of $\mathrm{CO}_{3}{ }^{-}$ions and in the presence of $\mathrm{Ca}^{2+}$ ions, $\mathrm{CaCo}_{3}$ precipitated and accumulated on the cell surface according to the Eqs. 9-11 $11^{53-55}$.

$$
\begin{gathered}
\mathrm{Ca}^{+2}+\text { cell }^{-} \rightarrow \text { Cell }-\mathrm{Ca}^{+2} \\
\mathrm{HCO}_{3}^{-} \leftrightarrow \mathrm{H}^{+}+\mathrm{CO}_{3}^{-2} \\
\text { Cell }-\mathrm{Ca}^{+2}+\mathrm{CO}_{3}^{-2} \rightarrow \text { Cell }-\mathrm{CaCO}_{3} \downarrow
\end{gathered}
$$

Actually, the ionic selectivity of the cell promotes $\mathrm{Ca}^{2+}$ ions to be adsorbed on the cell envelope more frequently to be accumulated inside it. As pointed out by Anbu et al. ${ }^{56}$, the cellular ATP-dependent pump, which is located close to outside of the cell, transfers $\mathrm{Ca}^{2+}$ ions actively extracellularly; which is coupled with $\mathrm{H}^{+}$uptake. Additionally, Desrosiers et al. ${ }^{57}$ and Norris et al..$^{58}$ referred that the extracellular concentration of $\mathrm{Ca}^{2+}$ ions is up to 103 times higher than intracellular concentration, hence great tendency for extracellular biodeposition. Once the $\mathrm{CaCO}_{3}$ nuclei is formed in supersaturated solution, the crystal growth begins through atom-by-atom addition and increase in particles size as described by Trushina et al. ${ }^{59}$. Figure 3 illustrated graphical diagram summarizing the whole process.

Regarding the bioremediation of $\mathrm{Pb}^{2+}$ and $\mathrm{Hg}^{2+}$, ICP-OES results of soluble metals denoted their transformation to insoluble form encapsulating within $\mathrm{CaCO}_{3}$ matrix. Such would be approved through the upcoming characterization approaches. The entrapment of both metals via microbially driven biomineralization process alleviated their toxicity through obstruction of their release and decreasing their availability. The incorporation of both metals into $\mathrm{CaCO}_{3}$ matrix occurred through substitution of $\mathrm{Ca}^{2+}$ with $\mathrm{Pb}^{2+}$ and $\mathrm{Hg}^{2+}$, especially with presence of unconsumed soluble $\mathrm{Ca}^{2+}$ in the range of $11.7-23 \%$, for both metals and under both conditions. This ionic exchange between divalent cations depends on several parameters such as metals hydrolysis constant, electronegativity, ionic radius, hydrated radius and atomic radius as reported by conventional theory ${ }^{24,60-62}$. In the current study, the probability of both metals to be accessed into the interstice of the precipitated crystals and also the similarity in ionic radii among $\mathrm{Ca}^{2+}, \mathrm{Pb}^{2+}$ and $\mathrm{Hg}^{2+}$ were suggested. Where, it records $0.1,0.119$ and $0.110 \mathrm{~nm}$ for $\mathrm{Ca}^{2+}, \mathrm{Pb}^{2+}$ and $\mathrm{Hg}^{2+}$, respectively ${ }^{63-65}$. In coincidence with our results, Chada et al. ${ }^{66}$ and $\mathrm{Zhu}$ and $\mathrm{Dittrich}^{24}$, assigned the existence of divalent cations such as $\mathrm{Cd}^{2+}, \mathrm{Pb}^{2+}, \mathrm{Sr}^{2+}, \mathrm{Zn}^{2+}$ and $\mathrm{Co}^{2+}$ in calcite crystals to their ionic radii that are closed to $\mathrm{Ca}^{2+}$. In the same extent, Mwandira et al. ${ }^{44}$ found that the ureolytic strain Pararhodobacter $s p$. detoxified $\mathrm{Pb}^{2+}$ completely in MICP process through its incorporation in calcite and vaterite lattice. Whereas, Qian et al ${ }^{67}$ attributed the removal of toxic $\mathrm{Cr}^{6+}$ and $\mathrm{Pb}^{2+}$ by ureolytic fungi Penicillium chrysogenum in MICP 

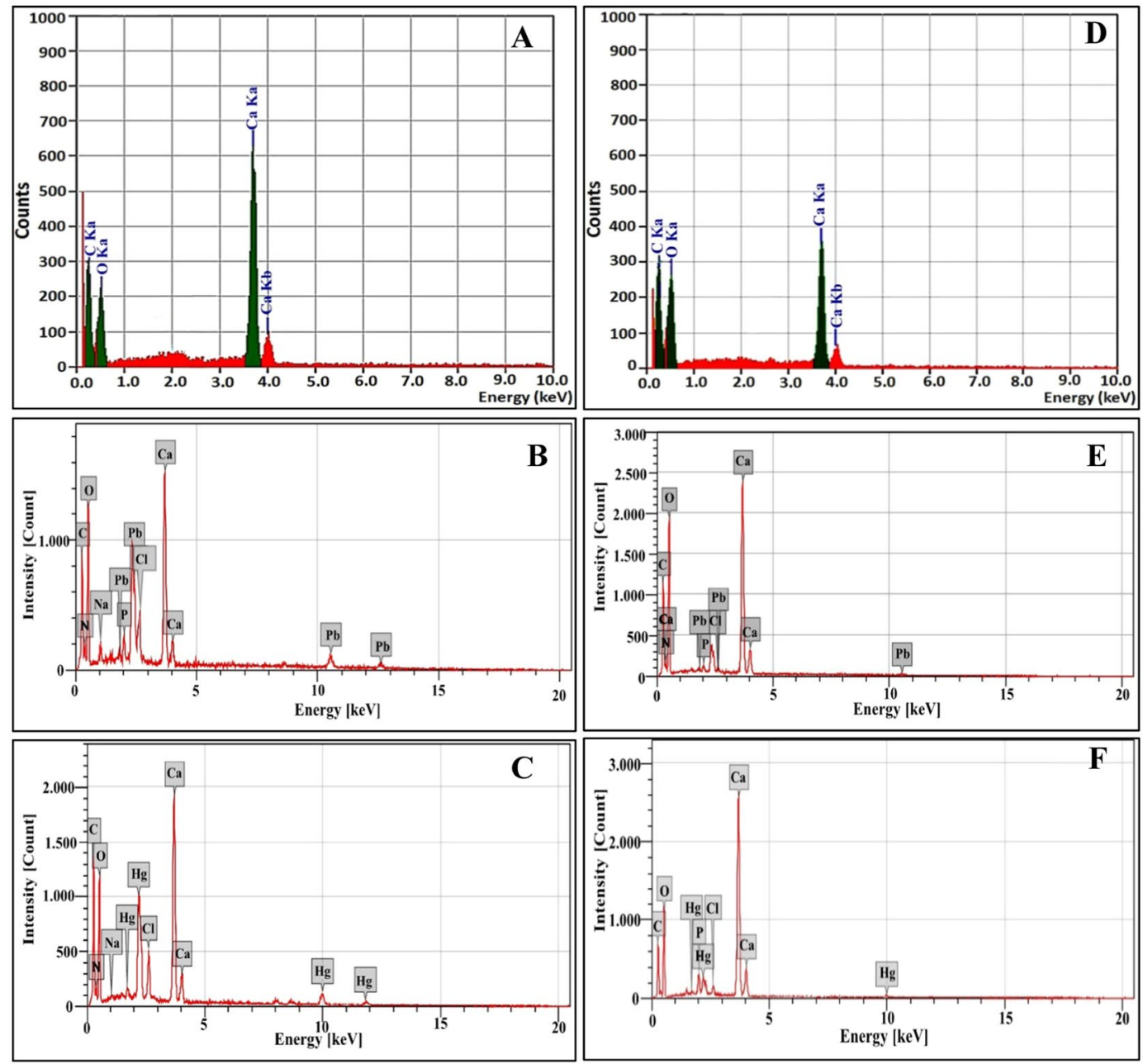

Figure 4. EDS profile of precipitated crystals biotic controls and remediated samples by strain 10B through aerobic and anaerobic nitrate reduction. (A) aerobic biotic control; (B) $\mathrm{Pb}^{2+}$ remediated crystals under aerobic conditions; (C) $\mathrm{Hg}^{2+}$ remediated crystals under aerobic conditions; (D) Anaerobic biotic control; (E) $\mathrm{Pb}^{2+}$ remediated crystals under anaerobic conditions and $(\mathbf{F}) \mathrm{Hg}^{2+}$ remediated crystals under anaerobic conditions.

process through the steady replacement of $\mathrm{CO}_{3}{ }^{2-}$ anion in calcite lattice. Despite sufficient removal of $\mathrm{Hg}^{2+}$, it required more time for detoxification in comparison to $\mathrm{Pb}^{2+}$. That could be ascribed to its more toxicity to the microbial cell due to its potent affinity for thiol (SH) groups of proteins. Therefore, prolonged time was required to be adapted for toxicity ${ }^{68}$. Additionally, microorganisms exhibit preference property for some certain metals over the others as elucidated by Halttunen et al. ${ }^{69}$.

Mineralogical analysis and biodeposits characterization. The obvious and full view of bioremediation efficiency based on MICP of strain 10B under aerobic and anaerobic nitrate reduction conditions would be achieved through EDS, XRD and SEM analysis. These analytical techniques were employed to characterize the precipitated crystals (biotic controls and remediated samples) as follows:

EDS. EDS microanalysis of crystals precipitated aerobically and anaerobically in biotic controls illustrated in Fig. 4A-D, respectively. Both spectra exhibited characteristic peaks at $0.277,0.525$ and $3.69 \mathrm{keV}$, which correspond the binding energies of $\mathrm{C}, \mathrm{O}$ and $\mathrm{Ca}$, respectively ${ }^{70,71}$. Additional peaks related to the binding energy of $\mathrm{Pb}$ were detected at $2.293 \mathrm{keV}$ with atomic percentage of 15.2 and $11.7 \%$ in aerobic and anaerobic remediated samples, respectively (Fig. 4B-E). EDS also showed the presence of $\mathrm{Hg}$ through the characteristic $\mathrm{M} \alpha$ and $\mathrm{M} \beta$ emission peaks at 2.19 and $2.28 \mathrm{keV}$, respectively, along with L $\alpha$ and $\mathrm{L} \beta$ peaks at 9.99 and $11.82 \mathrm{keV}$, respectively as demonstrated in Fig. 4C-F. Such results confirmed the involvement of $\mathrm{Pb}$ and $\mathrm{Hg}$ in calcareous remediated precipitations. Remarkably, the percentages of bioprecipitated $\mathrm{Pb}$ and $\mathrm{Hg}$ under oxic conditions were higher than anoxic one. Moreover, the remediated mercury percentages under both conditions were lower than lead, which agreed with ICP-OES results of remediated supernatants. Clearly, the presence of $\mathrm{N}$ and $\mathrm{P}$ peaks in considerable percentage reflected the biotic origin of the precipitates. In fact, such elements are intrinsic constituents of microbial cells biomolecules which comprise proteins, nucleic acids, phospholipids and lipopolysaccharides ${ }^{72}$. Besides, 

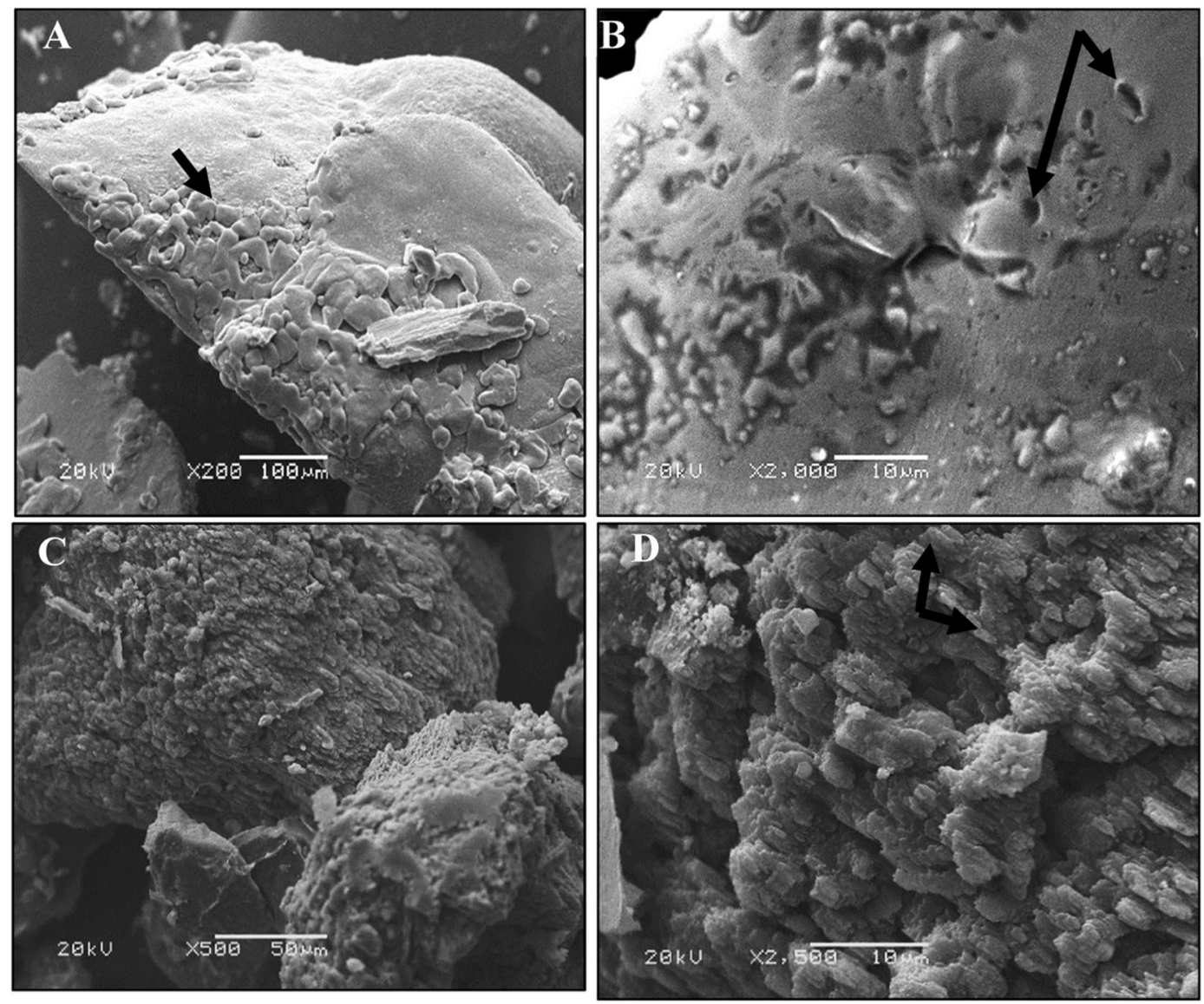

Figure 5. SEM micrographs of Carbonate crystals formed by biotic controls aerobically and anaerobically. $(\mathbf{A}, \mathbf{B})$ Aerobic culture; (C,D) Anaerobic culture. The arrows referred to the bacterial imprints and protrusions.

other peaks could be detected in a small percentage such as $\mathrm{Na}$ and $\mathrm{Cl}$ which considered being remaining of media components that integrated during MICP process. This result is in agreement with Han et al. ${ }^{73}$.

SEM. The detailed description of biotic controls aerobically and anaerobically was illustrated in Fig. 5. The aerobically mineralized crystals exhibited a fine smooth texture encompassing bacterial cells that were protruded or imprinted above the surfaces as denoted by arrows in Fig. 5A,B. On the other hand, large, rough and coarse particles with wrinkled surface were displayed under anaerobic conditions (Fig. 5C,D). Upon magnification, the calcified cells were assembled compactly into close-packed stacks like superstructures with size ranged from 2 to $5 \mu \mathrm{m}$. Similarly, Seifan et al. ${ }^{74}$ found differences in the shape and size of $\mathrm{CaCO}_{3}$ crystals sedimented by B. licheniformis ATCC 9789 and B. sphaericus NZRM 4381 throughout changing incubation conditions such as aeration and $\mathrm{pH}$.

However, some morphological and textural variations were observed in the bioremediated samples. The $\mathrm{Pb}^{2+}$ remediated grains showed well-defined faces crystal with rhombic, square as well as cubic shapes as pointed out by yellow arrows (Fig. 6A-C). Besides, the bioremediated crystals generated aerobically showed smooth edges with more angularity than those formed anaerobically. The close view image of aerobic remediated $\mathrm{Pb}^{2+}($ Fig. 6B) displayed layer-flake structures contained sponge like area with many holes. Such holes resembled bacterial cell shape which revealed the delimiting the cell contours by availability of precipitated minerals. Analogues results have been obtained by Rothenstein et al. ${ }^{75}$ and Silva-Castro et al. ${ }^{76}$. Further, magnified view of the anaerobically remediated $\mathrm{Pb}^{2+}$ depicted irregular flaks like matrix embedded with accumulation of calcified cells (Fig. 6D). Whereas, less crystallinity and amorphous shape of $\mathrm{Hg}^{2+}$ remediated bioliths were noticed, especially those deposited anaerobically (Fig. 6E-G). The magnified fields of both exhibited rough surface with no angularity as well. The calcified cells were clearly evident on the irregular surface of bioliths as referred by white head arrows (Fig. 6F-H). Moreover, many cavities were displayed on the surface of precipitates (Fig. 6F-H, red stealth arrows), reflecting bacterial imprints, which suggested to be the starting point for the aggregation of carbonate deposits. Commonly, at this stage, the calcified cells entered into death phase due to inhibition of nutrients exchange with the surrounding environment as stated by Silva-Castro et al..$^{76}$.

XRD. As depicted in Fig. 7, XRD spectra affirmed the heterotrophic precipitation of $\mathrm{CaCO}_{3}$ In the biotic controls under both incubation conditions, sharp, characteristic, distinguishable and broad diffraction peaks of calcite were identified at $2 \theta$ values of $29.50,36.04,39.51,43.31,47.51,48.65,56.71,60.81$ and 63.22 that were corresponding to Miller indices of (104) (110), (113), (202), (024), (116), (211), (214) and (125), respectively ${ }^{77,78}$ 

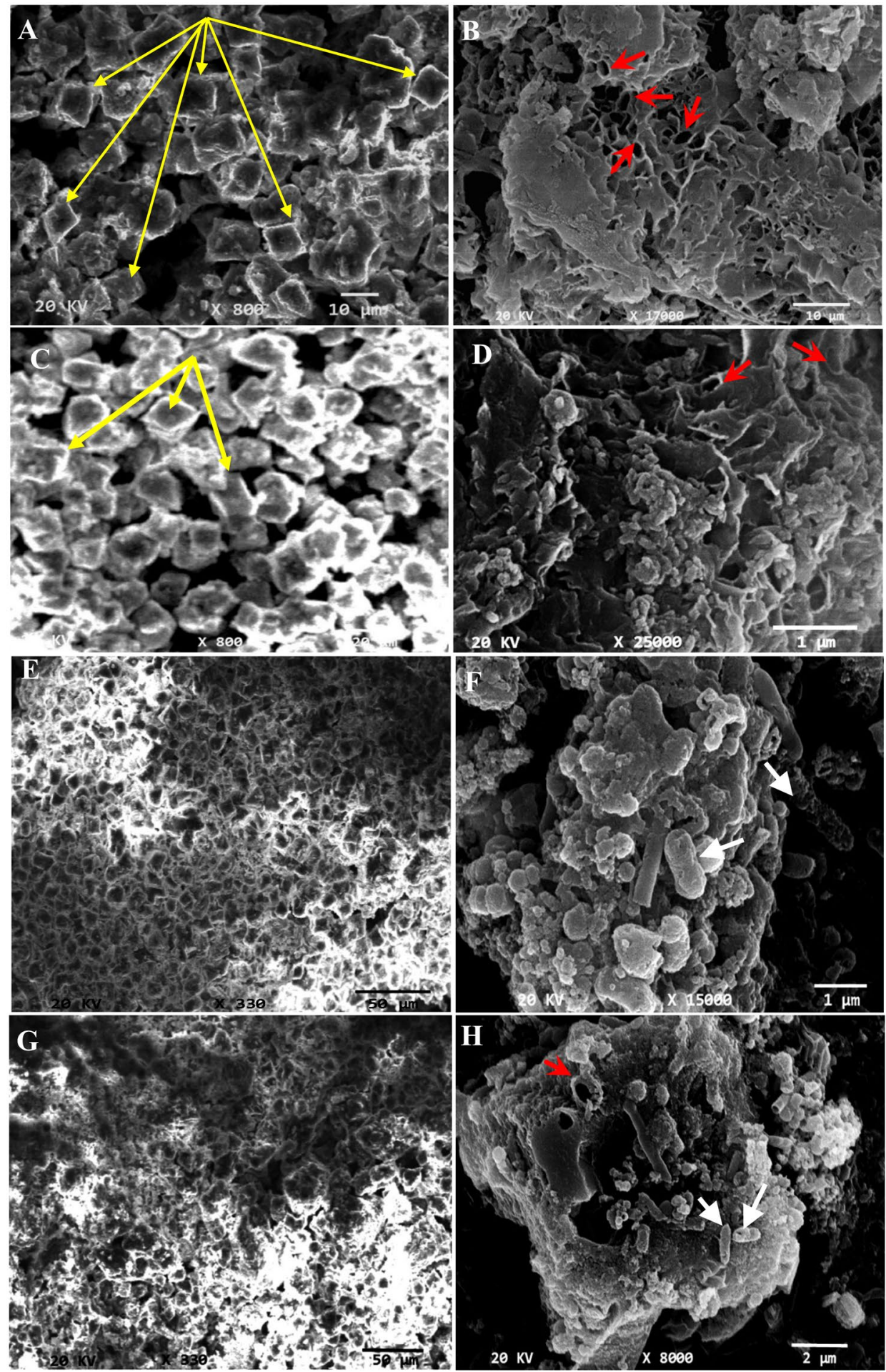

Figure 6. SEM micrographs of remediated crystals precipitated by strain $10 \mathrm{~B}$ through nitrate reduction process. $(\mathbf{A}, \mathbf{B}) \mathrm{Pb}^{2+}$ remediated crystals under aerobic conditions; (C,D) $\mathrm{Pb}^{2+}$ remediated crystals under anaerobic conditions; (E,F) $\mathrm{Hg}^{2+}$ remediated crystals under aerobic conditions; $(\mathbf{G}, \mathbf{H}) \mathrm{Hg}^{2+}$ remediated crystals under anaerobic conditions. The long yellow arrows referred to crystals shape; head white arrows referred to calcified bacterial cells; stealth red arrows referred to the bacterial imprint.

(Fig. 7A-D). These peaks corroborate with the standard ICDD PDF 5-0586 as referred by Tas, ${ }^{79}$. Generally, XRD crystallographic patterns of all bioremediated samples declared that calcite was the dominant component, which matched with EDS results. The bacterial cells mineralized with calcite together with the remediated metals have been previously mentioned to be common biomineralization products ${ }^{61,67}$. In addition, the diffraction peaks of calcite, especially at $2 \theta$ values of 29.50 were shifted to right as a consequence of the replacement or integration of 

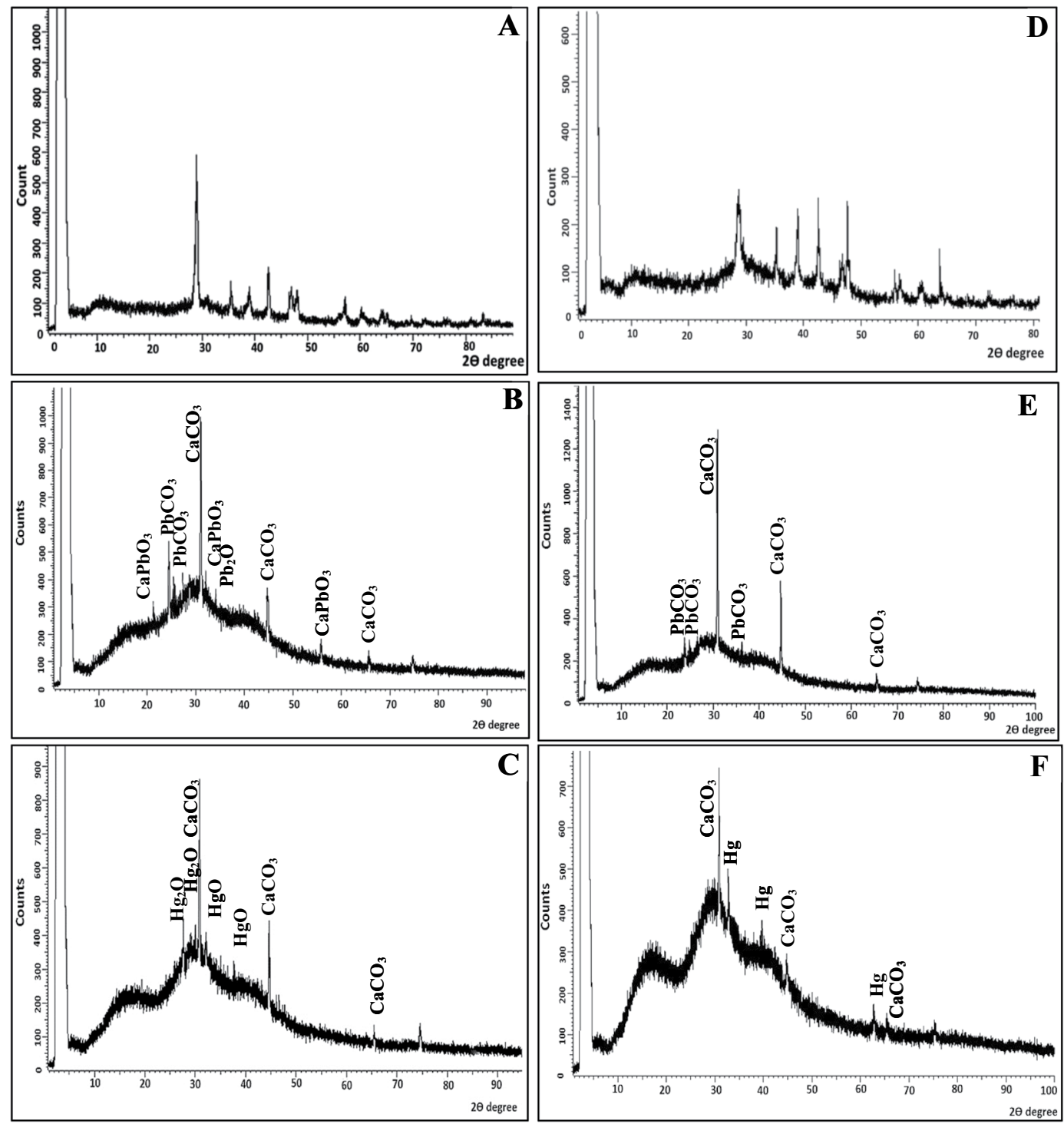

Figure 7. XRD pattern of precipitated crystals biotic controls and remediated samples by strain $10 \mathrm{~B}$ through aerobic and anaerobic nitrate reduction. (A) Aerobic biotic control; (B) $\mathrm{Pb}^{2+}$ remediated crystals under aerobic conditions; (C) $\mathrm{Hg}^{2+}$ remediated crystals under aerobic conditions; (D) Anaerobic biotic control; (E) $\mathrm{Pb}^{2+}$ remediated crystals under anaerobic conditions and (F) $\mathrm{Hg}^{2+}$ remediated crystals under anaerobic conditions.

remediated metals in calcite matrix. Reinforces this finding reported by Han et al. ${ }^{80}$, who found that $\mathrm{Mg}^{2+}$ deteriorated the crystal growth of calcite which thereby lead to right shift in the (104) diffraction peak.

In both $\mathrm{Pb}^{2+}$-remediated samples, the identified phase of $\mathrm{Pb}^{2+}$ was cerussite $\left(\mathrm{PbCO}_{3}\right)$; implying simultaneous deposition of $\mathrm{Pb}^{2+}$ with $\mathrm{CO}_{3}{ }^{2-}$ during calcite precipitation induced by nitrate reduction process (Fig. 7B-E). Furthermore, other weak peaks correspond to other phases such as lead oxide $\left(\mathrm{Pb}_{2} \mathrm{O}\right)$ and calcium lead oxide $\left(\mathrm{CaPbO}_{3}\right)$ were detected as a product of the bacterial mineralization in the aerobically remediated sample (Fig. 7B). The presence of such phases could be attributed to the uncontrolled metabolic activity that aerobically generated different oxide anions that substituted $\mathrm{CO}_{3}{ }^{2-}$ group. This result was consistent with the Achal et al. ${ }^{12}$, who stated that Kocuria flava detoxified $\mathrm{Pb}^{2+}$ stress in the contaminated soil through ureolysis process and assigned the formation of different $\mathrm{Pb}^{2+}$ phases (carbonate and oxides) to the replacement of $\mathrm{CO}_{3}{ }^{2-}$ group with $\mathrm{Pb}$ oxyanions. Moreover, Achal et al. ${ }^{81}$ reported the substitution of As (III) oxyanion for $\mathrm{CO}_{3}{ }^{2-}$ group via ureolytic Sporosarcina ginsengisoli CR5 in calcite.

Regarding $\mathrm{Hg}^{2+}$-MICP samples, XRD spectra revealed strong calcite peaks along with weak peaks hardly detected due to background noise; arising from bacterial biomass (Fig. 7C-F). These weak diffraction peaks match those of the standard spectrum PDF 74-0039, PDF 01-0896 and PDF 73-2218, which were assigned to $\mathrm{Hg}, \mathrm{HgO}$ and $\mathrm{Hg}_{2} \mathrm{O}$, respectively. In spite of the clear precipitation of $\mathrm{HgCO}_{3}$ was not obtained, the remediation process achieved within stable solid phase. Such result could be explained by the flexibility of biogenic calcite structure, including sufficient porosity and surface area, which promoted the incorporation of $\mathrm{Hg}^{2+}$ into calcite lattice as documented by Achal et al. ${ }^{72}$ and Qian $e t ~ a l .{ }^{67}$. The electronegativity of biogenic calcite suggested 
favoring the gradual capturing of $\mathrm{Hg}^{2+}$ during the crystal growth stage of calcite precipitates. Accordingly, in this case, the produced calcite was acting efficiently not only in the absorption, but also sequestering the toxic metal in stable precipitate. Similarly, Sun et al. ${ }^{82}$ recorded such phenomena in removal of Cr(VI) by chemical precipitation. Furthermore, durable encapsulation of $\mathrm{Zn}^{2+}$ ions in $\mathrm{Ca}-\mathrm{Zn}-\mathrm{CO}_{3}$ solid solution was obtained by concurrent $\mathrm{CaCO}_{3}$ formation and $\mathrm{Zn}^{2+}$ sequestration of $\mathrm{S}$. pasteurii within 7 days remediation process ${ }^{61}$.

Virtually, mineralogical characterization techniques confirmed the presence of $\mathrm{Pb}^{2+} / \mathrm{Hg}^{2+}$-calcite coprecipitated products in the examined remediated sample as possible indirect action of nitrate reductases. In addition, they gave insight on scavenging role of calcite in chelating active soluble heavy metals. Meanwhile, the adsorbed metals were stabilized in calcite matrix and coprecipitated by additional calcite particles which generated continuously during MICP process. Such mixed metal inclusions donated a more potent trap than adsorption which occurs mainly superficially and relies on bonding specifications between adsorbents and adsorbate ${ }^{83}$. It is noteworthy to mention that $\mathrm{CaCO}_{3}$ possesses adsorptive capacity and has the ability to retain divalent metals as recorded by Chada et al. ${ }^{66}$. That makes it a good ecofriendly agent to apply practically in the uptake of toxic metals arose from anthropogenic activities.

Recently, hydroxide precipitation approach has been utilized effectively in removal of heavy metals ${ }^{84}$. Nonetheless, hydroxide precipitates suffering from redissolution in water through formation of soluble anionic hydroxyl complexes $^{85}$. Hence, the immobilization of toxic metals in carbonate structure via MICP process deemed as alternative approach to alleviate active metals toxicity through limiting their mobility and bio-availability, fix them in stabilized solid and subsequently obstructed their release from calcite lattice to the surrounding ecosystem ${ }^{61}$. In tandem with the current results, Qian et al. ${ }^{67}$ manifested that the enhancement of heavy metals removal was conjugated with carbonate precipitations. Interestingly, Sdiri and Higashi, ${ }^{60}$ declared the promising utilization of natural limestones in removal of $10 \mathrm{mg} / \mathrm{L}$ of $\mathrm{Pb}^{2+}$ in $6 \mathrm{hrs}$. In this sense, Hu et al. ${ }^{86}$ utilized $\mathrm{CaCO}_{3}$ as potent alternative to $\mathrm{Ca}(\mathrm{OH})_{2}$ to remediate $\mathrm{Cu}^{2+}$ with $99.7 \%$ removal efficiency. Moreover, Fazlollahi et al. ${ }^{87}$ showed that $\mathrm{CaCO}_{3}$ coprecipitation technique reduced mercury content in contaminated brine from 0.5 to $0.055 \mathrm{ppm}$ by $89 \%$ elimination efficacy.

It is remarkable to mention that Qian et al. ${ }^{67}$ found that Penicillium chrysogenum CS1 removed $98.8 \% \mathrm{of} \mathrm{Pb}^{2+}$ from initial concentration $200 \mathrm{mg}$ within 12 days. Kang et al.$^{45}$ stated that ureolytic strains Enterobacter cloacae $\mathrm{KJ}-46$ and $\mathrm{KJ}-47$ removed $60 \%$ of $\mathrm{Pb}^{2+}$ from initial concentration of 7.2 and $5.9 \mathrm{mg} / \mathrm{L}$, respectively within $48 \mathrm{hr}$. incubation. Further, François et al. ${ }^{71}$ documented that Kocuria rosea EP1, Ochrobactrum sp. HG16 and Bacillus sp. CM111 remediated $100 \mu \mathrm{M}$ of mercury through biosorption. Moreover, Pseudomonas putida succeeded in removal of $4 \mathrm{ppm}$ of $\mathrm{Hg}^{2+}$ in two days incubation through volatilization mechanism ${ }^{88}$. Accordingly, strain 10B seemed to be characteristic and considered as a promising tool to remediate high concentrations of $\mathrm{Ca}^{2+}, \mathrm{Pb}^{2+}$ and $\mathrm{Hg}^{2+}$ under different aeration conditions and in appropriate frame of time. In addition, the higher stability of biogenic carbonate minerals promotes its recruitment in situ bioremediation of different contaminated environmental systems such as soil, water and wastewater. Where, its precipitated nature without dispersed pattern facilitates its separation without the requirement to additional step such as filtration, coagulation or flocculation. Finally, the remediation of heavy metals through MICP seems to be advantageous, eco-friendly, sustainable approach and potent alternative to the chemical process.

\section{Materials and Methods}

Microorganism, cultural conditions and enzyme assay. The bacterial strain Proteus mirabilis 10B is a local isolate formerly identified and published as a nitrate reducer and metals nanobiofactory ${ }^{89}$. Both NAP and NAR genes were detected, identified and submitted to the Genbank as described in details elsewhere ${ }^{72}$. The strain was stored in glycerol $(20 \%, \mathrm{v} / \mathrm{v})$ at $-20^{\circ} \mathrm{C}$ for the forthcoming investigations. The basal medium $(\mathrm{g} / \mathrm{L})$ of the following ingredients was used for the optimization process of NAP and NAR enzymes under aerobic and anaerobic conditions: $\mathrm{NaNO}_{3} 5.0, \mathrm{~K}_{2} \mathrm{HPO}_{4} \cdot 7 \mathrm{H}_{2} \mathrm{O} 1.0, \mathrm{KH}_{2} \mathrm{PO}_{4} 3.0, \mathrm{MgSO}_{4} \cdot 7 \mathrm{H}_{2} \mathrm{O}$ 0.12, disodium citrate $\left(\mathrm{C}_{6} \mathrm{H}_{6} \mathrm{O}_{7} \mathrm{Na}_{2}\right)$ 7.5, $\mathrm{NaCl} 0.5, \mathrm{ZnSO}_{4} 0.31, \mathrm{MnCl}_{2} \cdot 4 \mathrm{H}_{2} \mathrm{O} 0.03, \mathrm{FeCL}_{2} \cdot 4 \mathrm{H}_{2} \mathrm{O} 0.24, \mathrm{Na}_{2} \mathrm{MoO}_{4} \cdot 2 \mathrm{H}_{2} \mathrm{O} 0.015, \mathrm{CuSO}_{4} \cdot 5 \mathrm{H}_{2} \mathrm{O} 0.06$, $\mathrm{CoCl}_{2} \cdot 6 \mathrm{H}_{2} \mathrm{O} 0.04$ and $\mathrm{H}_{3} \mathrm{BO}_{3} 0.057$ at $\mathrm{pH} 7.0 \pm 0.2$. About $0.5 \mathrm{McF}$ arland equivalents to about $1.5 \times 10^{8} \mathrm{CFU} /$ $\mathrm{ml}$ was inoculated in $250 \mathrm{~mL}$ Erlenmeyer flasks containing $100 \mathrm{~mL}$ of the medium and incubated at $30^{\circ} \mathrm{C}$ in an orbital shaker (STUART SI500) at $150 \mathrm{rpm}$ (for NAP) and anaerobically (for NAR) as described by Jun ${ }^{90}$ and Siddiqui et al. ${ }^{91}$. After the incubation period, the cells were centrifuged at $10.000 \mathrm{Xg}$ for $20 \mathrm{~min}$ at $4{ }^{\circ} \mathrm{C}$ and the harvested cells were used to determine NAP and NAR activities according to the procedure followed by Zaki et $a l^{72}$. One unit of NAP/NAR activity was identified as the amount of enzyme that catalyzes the formation of $1 \mu \mathrm{mol}$ of nitrite per minute or $1 \mu \mathrm{mol}$ of nitrate reduced per minute under standard assay conditions.

Optimization of NAP and NAR activities by design of experiment (DOE). Screening for significant factors influence the NAP and NAR activities by Plackett-Burman Design (PBD). PBD is a two-level factorial design that is dedicated to screen and identify the controlled experimental factors (nutritional, environmental and incubation conditions) based on their main effect on elevating NAP and NAR activities. PBD allows the investigation of $(n-1)$ variables with at least $n$ experiments. Each variable is represented at two levels, high $(+)$ and low $(-)$. Herein, a total of $16(n)$ variables with two-level concentrations were studied in twenty experiments matrix, as indicated in Tables (1 and 2). Each experiment was performed in triplicate and an average of NAP and NAR activities were calculated as response ${ }^{25}$. Plackett-Burman experimental design is based on the first order model (Eq. 12):

$$
\mathrm{Y}=\beta_{\mathrm{O}}+\Sigma \beta \mathrm{iXi}
$$

where, $\mathrm{Y}$ is the response or dependent variable (NAP/NAR activity); it will always be the variable we aim to predict, $\beta_{\mathrm{o}}$ is the model intercept and $\beta \mathrm{i}$ is the linear coefficient, and $\mathrm{Xi}$ is the level of the independent variable. From the statistical analysis, the main effect was used to elucidate the significance of variables depending on their nature, i.e., positive or negative effect on the production process. 
Central composite design (CCD) method. This stage was devoted to analyze the interaction among significant variables and also determine their optimal levels. In this study, five different significant variables identified from PBD to greatly influence NAP and NAR activities and were investigated at 5 experimental levels: $-\alpha,-1,0,+1$, and $+\alpha$. The concentrations of the screened variable at each level in the 32-trail matrix are listed in Table 3. All of the experiments were conducted in triplicate, and the average enzyme activity obtained was taken as the dependent variable or response $(\mathrm{Y})^{26}$. For statistical calculation, the relationship between the coded and actual values is described by Eq. 13:

$$
\mathrm{Xi}=\mathrm{Ui}-\mathrm{Ui}_{0} / \Delta \mathrm{Ui}
$$

where $X i$ is the coded value of the $i$ th variable, $U i$ is the actual value of the $i$ th variable, $U_{0}$ is the actual value of the $i$ th variable at the center point and $\Delta \mathrm{Ui}$ is the step change of variable. The second order polynomial structured represented in Eq. 14:

$$
Y=\beta_{0}+\beta_{1} X_{1}+\beta_{2} X_{2}+\beta_{3} X_{3}+\beta_{11} X_{11}+\beta_{22} X_{22}+\beta_{33} X_{33}+\beta_{12} X_{1} X_{2}+\beta_{13} X_{1} X_{3}+\beta_{23} X_{2} X_{3}
$$

where: $Y$ is the predicted response; $\mathrm{X}_{1}, \mathrm{X}_{2}, \mathrm{X}_{3}$ are input variables which influence the response variable $\mathrm{Y} ; \beta_{0}$, intercept; $\beta_{1}, \beta_{2}$ and $\beta_{3}$ linear coefficients; $\beta_{11}, \beta_{22}$ and $\beta_{33}$, squared or quadratic coefficients $\beta_{12}, \beta_{13}$, and $\beta_{23}$ interaction coefficients

Statistical analysis. The statistical software Minitab 14.0 (Minitab Inc., Pennsylvania, USA) was used to perform the experimental designs "trials matrices" and statistical analysis of PDB and CCD. Besides, three-dimensional surface plots and two-dimensional contour plots were constructed to illustrate the relationship between the responses and the different levels of each variables utilized in this study. In addition, the optimizer tool was used to predict the optimum level of experimental factors to maximize response ${ }^{92}$.

Validation of experimental model. The statistical model was validated by measuring NAP and NAR activities under conditions predicted by the model and comparing the values to those obtained with basal media ${ }^{26}$.

Bioremediation of $\mathrm{Pb}^{2+}$ and $\mathrm{Hg}^{2+}$ in MICP process. The performance of strain $10 \mathrm{~B}$ in $\mathrm{Pb}^{2+}$ and $\mathrm{Hg}^{2+}$ bioremediation through aerobic/anaerobic nitrate reduction was examined and confirmed in broth state at flask level. The biomineralization media (the optimized media contained $\mathrm{Ca}\left(\mathrm{NO}_{3}\right)_{2}$ instead of $\left.\mathrm{NaNO}_{3}\right)$ was supplemented with $1.7 \mathrm{mM}(350 \mathrm{ppm})$ of $\mathrm{Pb}\left(\mathrm{CH}_{3} \mathrm{COO}\right)_{2} .3 \mathrm{H}_{2} \mathrm{O}$ and $\mathrm{HgCL}_{2}$. Such concentration was selected according to minimal inhibitory concentration (MIC) test (data not shown). The flasks were inoculated and incubated under aerobic and anaerobic conditions at $30^{\circ} \mathrm{C}$ for 10 days. Two controls were run in parallel; the abiotic or negative control contains uninoculated medium and biotic controls containing inoculated biomineralization media without $\mathrm{Pb}$ $\left(\mathrm{CH}_{3} \mathrm{COO}\right)_{2} \cdot 3 \mathrm{H}_{2} \mathrm{O}$ or $\mathrm{HgCL}_{2}$. The dynamics of bioremediation was evaluated during the biomineralization process, at a constant interval time ( $6 \mathrm{hr}$.) through assessment of some parameters, including bacterial count, NAP/NAR activity, $\mathrm{pH}$, concentrations of soluble $\mathrm{Ca}^{2+}, \mathrm{Pb}^{2+}, \mathrm{Hg}^{2+}, \mathrm{NO}_{3}{ }^{-}$and $\mathrm{NO}_{2}{ }^{-}$. A pH meter (PB-10, Sartorius AG) was used to measure the $\mathrm{pH}$; however, $\mathrm{NO}_{3}{ }^{-}$and $\mathrm{NO}_{2}{ }^{-}$were estimated according to the methods described by $\mathrm{APHA}^{93}$. The concentration of soluble $\mathrm{Ca}^{2+}, \mathrm{Pb}^{2+}, \mathrm{Hg}^{2+}$ were determined by inductively coupled plasma optical emission spectrometer (Agilent ICP-OES 5110DVD) (Central Lab, Alexandria university). Whereas, NAP/NAR activities were determined as described previously; the bacterial count was evaluated by pour plate method. All experiments were conducted in triplicate and the mean values were considered. At the end of the incubation period, all precipitates were centrifuged at $10.000 \mathrm{Xg}$ for $20 \mathrm{~min}$ and subjected to mineralogical analysis ${ }^{14}$.

Mineralogical analysis and biodeposits characterization. For assessment the identity, morphology, microstructure and chemical constituents of precipitated samples, XRD, SEM and EDS were utilized. XRD was carried out to identify the precipitated minerals by Bruker MeaSrv (D2-208219) diffractometer (Central lab, Faculty of Science, Alexandria University) with $\mathrm{Cu} \mathrm{K} \alpha$ tube anode, applying $30 \mathrm{KV} / 30 \mathrm{~mA}$. Scans were run from $0^{\circ}$ to $100^{\circ} 2 \theta$ at a scanning speed of $2^{\circ} / \mathrm{min}$. However, SEM (JEOL JSM 6360LA, Japan - Advanced Technologies and New Materials Research Institute (ATNMRI), SRTA-City) was used to visualize the morphology of crystals. The elemental composition of the crystals was analyzed with energy dispersive spectrometer SEM (JEOL JSM 6360LA, Japan-Advanced Technologies and New Materials Research Institute (ATNMRI) SRTA-City and JSM5300, JEOL Japan, Electron microscope unit-Alexandria University) at an operating voltage of $20 \mathrm{kV}^{94}$.

\section{Conclusion}

In conclusion, to the best of our knowledge, this is the first report of an attempt to successfully remediate $\mathrm{Pb}^{2+}$ and $\mathrm{Hg}^{2+}$ via $\mathrm{CaCO}_{3}$ precipitation induced by Proteus mirabilis $10 \mathrm{~B}$ under aerobic and anaerobic nitrate utilization. Therefore, the current study focused on optimization of nitrate reductases aerobically and anaerobically. On the optimized precipitating media, the effectiveness of MICP for successful elimination of $\mathrm{Pb}^{2+}{\text { and } \mathrm{Hg}^{2+}}_{\text {was }}$ examined. The parametric changes of media chemistry in remediation trials were demonstrated. Experimental results denoted the sufficient removal of $\mathrm{Pb}^{2+}$ (95.2 and 91.1\%) and $\mathrm{Hg}^{2+}$ (92 and 88.3\%) from initial $350 \mathrm{ppm}$ following incubation at (144 and $168 \mathrm{hr}$.) and (168 and 186 hr.) under aerobic and anaerobic conditions, respectively. Mineralogical analysis including EDS, SEM and XRD confirmed the existence of calcite and cerussite in both $\mathrm{Pb}^{2+}$ remediated samples. However, $\mathrm{HgO}$ and $\mathrm{Hg}$, conjugated with calcite, were observed in aerobic and anaerobic $\mathrm{Hg}^{2+}$ remediated samples, respectively; which emphasized the uptake of soluble toxic metals and their transformation to insoluble stable form entrapped in calcite lattice. Such metal-calcite deposits provided an advantage in limiting the leaching of metals from carbonate bound complex to the surrounding environment. Such can be considered as a good strategy for cost-effective, environmentally friendly and effective method for heavy metals bioremediation. 


\section{Data availability}

All data generated or analyzed during this study are included in this article (and its Supplementary Information File).

Received: 17 October 2019; Accepted: 11 February 2020;

Published online: 04 March 2020

\section{References}

1. Shanab, S., Essa, A. \& Shalaby, E. Bioremoval capacity of three heavy metals by some microalgae species (Egyptian Isolates). Plant Signat. \& Behav. 7, 1-8 (2012)

2. Sharma, S. et al. Physical, Chemical and Phytoremediation Technique for Removal of Heavy. Metals. J. Heavy Metal Toxic. \& Dis. 2, $1-15$ (2016).

3. Masindi, V. \& Muedi, K. Chapter 7: Environmental Contamination by Heavy Metals, https://www.intechopen.com/books/heavymetals/environmental-contamination-by-heavy-metals (2018).

4. Zhang, R., Wilson, V., Hou, A. \& Meng, G. Source of lead pollution, its influence on public health and the countermeasures. Int. J. of Health, Animal sci. \& Food saf. 2, 18-31 (2015).

5. Li, R. et al. Mercury pollutions in vegetables, grains and soils from areas surrounding coal-fired power plants. Sci. Rep. 7, 46545 (2017).

6. Gunatilake, S. Methods of Removing Heavy Metals from Industrial Wastewater. J. Multidisciplinary Eng. Sci. Stud. 1, 12-18 (2015).

7. Agarwal, R. \& Singh, K. Methodologies for removal of heavy metal ions from wastewater: an overview. Interdisciplinary Environ. Rev. 18, 124-141 (2017).

8. Bojórquez, C., Espericueta, M. \& Voltolina, D. Removal of cadmium and lead by adapted strains of Pseudomonas aeruginosa and Enterobacter cloacae. Rev. Int. Contam. Ambie. 32, 407-412 (2016).

9. Tariq, W. et al. Removal of heavy metals from chemical industrial wastewater using agro based bio-sorbents. Acta Chemica Malaysia. 2, 9-14 (2018).

10. Fosso-kankeu, E., Mulaba-bafubiandi, A., Marjanovic, M. \& Barnard T. Optimising the removal by B. subtilis and B. bacterium of metals found around mining areas: evaluation of the effect of physical and physiological parameters. Inter. Mine Water Conf. Pretoria, South Africa (2009).

11. Gupta, A. et al. Microbes as Potential Tool for Remediation of Heavy Metals: A Review. J. Microb. Biochem. Technol. 8, 364-372 (2016).

12. Achal, V., Pan, X., Zhang, D. \& Fu, Q. Bioremediation of Pb-Contaminated Soil Based on Microbially Induced Calcite Precipitation. J. Microbiol. Biotechnol. 22(2), 244-247 (2012).

13. Achal, V. \& Pan, X. Characterization of urease and carbonic anhydrase producing bacteria and their role in calcite precipitation. Curr. Microbiol. 62, 894-902 (2011).

14. Yang, J. et al. Bioimmobilization of Heavy Metals in Acidic Copper Mine Tailings Soil. Geomicrobiol. J. 33, 261-266 (2016).

15. Marvasi, M. et al. Importance of B4 Medium in Determining Organomineralization Potential of Bacterial Environmental Isolates. Geomicrobiol J. 29, 916-924 (2012).

16. Caicedo-Pineda, G., Prada-Fonseca, M., Casas-Botero, A. \& Martínez-Tejada, H. Effect of the tryptone concentration on the calcium carbonate biomineralization mediated by Bacillus cereus. DYNA 85, 69-75 (2018).

17. Seifan, M., Ebrahiminezhad, A., Ghasemi, Y., Samani, A. \& Berenjian, A. The role of magnetic iron oxide nanoparticles in the bacterially induced calcium carbonate precipitation. Appl. Microbiol. Biotechnol. 102, 3595-3606 (2018).

18. Lee, Y. \& Park, W. Current challenges and future directions for bacterial self-healing concrete. Appl. Microbiol. \& Biotechnol. 102, 3059-3070 (2018).

19. Ariyanti, D., Handayani, N. \& Hadiyanto, H. Feasibility of Using Microalgae for Biocement Production through Biocementation. J Bioproces. Biotechniq. 2 (2012).

20. Almahamedh, H. Sulfate Reducing Bacteria Influenced Calcium Carbonate Precipitation. NACE international corrosion and EXPO (2013).

21. Montano-Salazar, S., Lizarazo-Marriaga, J. \& Pedro, B. Isolation and Potential Biocementation of Calcite Precipitation Inducing Bacteria from Colombian Buildings. Curr. Microbiol. 75, 256-265 (2018).

22. Rautaray, D., Ahmad, A. \& Sastry, M. Biological synthesis of metal carbonate minerals using fungi and actinomycetes. J. Mater. Chem. 14, 2333-2340 (2004).

23. Hamdan, N. Carbonate Mineral Precipitation for Soil Improvement through Microbial Denitrification. MSc. Thesis. Arizona State University (2013).

24. Zhu, T. \& Dittrich, M. Carbonate Precipitation through Microbial Activities in Natural environment, and Their Potential in Biotechnology: A Review. Frontiers in Bioeng. \& Biotechnol. 4, 1-21 (2016).

25. Abu-Elreesh, G., El-Shall, H., Eltarahony, M. \& Abdelhaleem, D. Conversion of Cost-Effective agricultural wastes into valued oil using the fungus Curvularia Sp: Isolation, Optimization and Statistical analysis. Biosci. Res. 16, 3006-3024 (2019).

26. El-Naggar, N., Soliman, H. \& El-Shweihy, N. Extracellular cholesterol oxidase production by Streptomyces aegyptia, in vitro anticancer activities against rhabdomyosarcoma, breast cancer cell-lines and in vivo apoptosis. Sci. Rep. 8 (2018).

27. Alshaibani, A., Yaakob, Z., Alsobaai, A. \& Sahri, M. Optimization of $\mathrm{Pd}-\beta / \gamma \mathrm{Al}_{2} \mathrm{O}_{3}$ catalyst preparation for palm oil hydrogenation response surface methodology (RSM). Braz. J. Chemic. Eng. 31, 69-78 (2014).

28. Wang et al. Medium optimization of L(+)-lactic acid production by Genome shuffled Lactobacillus rhamonsus Lc-F34 from agriculture wastes using statistical tools. Resources, env. \& eng. - Xie(ed.). Taylor \& Francis group 395-366 (2015).

29. Anuar, N., Adnan, A., Saat, N., Aziz, N. \& Taha, R. Optimization of Extraction Parameters by Using Response Surface Methodology, Purification, and Identification of Anthocyanin Pigments in Melastoma malabathricum Fruit. The Scientific World J. 2013 (2013).

30. Zainal, S., Nadzirah, K., Noriham, A. \& Normah, I. Optimisation of beef tenderisation treated with bromelain using response surface methodology (RSM). Agric. Sci. 4, 65-72 (2013).

31. Ranganath, M., Vipin, N., Kumar, N. \& Srivastava, R. Surface Finish Monitoring in CNC Turning Using RSM and Taguchi. Techniques. Inter. J. Emerg. Technol. \& Adv. Eng. 4, 171-179 (2014).

32. Marangon, J. et al. Substrate-dependent modulation of the enzymatic catalytic activity: Reduction of nitrate, chlorate and perchlorate by respiratory nitrate reductase from Marinobacter hydrocarbonoclasticus 617. Biochim. et Biophys. Acta. 1817, 1072-1082 (2012).

33. Kirchman, D., Hoffman, K., Weaver, R. \& Hutchins, D. Regulation of growth and energetics of a marine bacterium by nitrogen source and iron availability. Mar. Ecol. Prog. Ser. 250, 291-296 (2003).

34. Eltarahony, M., Zaki, S., Kheiralla, Z. \& Abd-El-haleem, D. Biogenic synthesis of Iron oxide nanoparticles via optimization of nitrate reductase Enzyme using statistical experimental design. J. Adv. Biotechnol. 5, 667-684 (2016-b).

35. He, T. \& Li, Z. Identification and denitrification characterization of a novel hypothermia and aerobic nitritedenitrifying bacterium, Arthrobacter arilaitensis strain Y-10. Desalin. Water Treat. 57, 19181-19189 (2015).

36. Huang, T. et al. Nitrogen Removal Characteristics of a Newly Isolated Indigenous Aerobic Denitrifier from Oligotrophic Drinking Water Reservoir, Zoogloea sp. N299. Inter. J. Mol. Sci. 16, 10038-10060 (2015). 
37. Gamez, V., Sierra-Alvarez, R., Waltz, M. \& Field, J. Anaerobic degradation of citrate under sulfate reducing and methanogenic conditions. Biodegrad. 20, 499-510 (2009).

38. Li, N., Pan, Y., Zhang, N., Wanga, X. \& Zhou, W. The bio-reduction of chromate with periplasmic reductase using a novel isolated strain Pseudoalteromonas sp. CF10-13. RSC Adv. 6, 106600-106607 (2016).

39. Ko, W., Chen, B. \& Chiu, C. Effect of Incubation Conditions on the Reduction of Nitrate to Nitrite by Micrococcus roseus and Escherichia coli O157: H7. J. Food Drug Analy. 11, 164-170 (2003).

40. Mahmooda, Q. et al. Isolation of Ochrobactrum sp.QZ2 from sulfide and nitrite treatment system. J. Hazard. Mat. 165, 558-565 (2009).

41. Drtil, M., Nemeth, P., Kucman, K., Bodik, I. \& Kasperek, V. Acidobasic balances in the course of heterotrophic denitrification. Water Res. 29, 1353-1360 (1995).

42. Aoki, K., Shinke, R. \& Nishira, H. Isolation and Identification of Respiratory Nitrate Reductase-Producing Bacteria from soli and production of enzyme. Agric. \& Biological Chem. 45, 817-822 (1981).

43. Ilbert, M. \& Bonnefoy, V. Insight into the evolution of the iron oxidation pathways. Biochimica et Biophysica Acta. 1827, 161-175 (2013).

44. Mwandira, W., Nakashimab, K. \& Kawasaki, S. Bioremediation of lead-contaminated mine waste by Pararhodobacter sp. based on the microbially induced calcium carbonate precipitation technique and its effects on strength of coarse- and fine-grained sand. Ecol. Eng. 109, 57-64 (2017).

45. Kang, C. et al. Bioremediation of lead by ureolytic bacteria isolated from soil at abandoned metal mines in South Korea. Ecol. Eng. 74, 402-407 (2015).

46. Singh, R. et al. Metabolism Induced $\mathrm{CaCO}_{3}$ Biomineralization During Reactive Transport in Porous Media: Implications for Porosity Alteration. Environ. Sci. Technol. 20, 12094-12104 (2015).

47. O’Donnell, S., Rittmann, B. \& Kavazanjian, E. Factors Controlling Microbially Induced Desaturation and Precipitation (MIDP) via Denitrification during Continuous Flow. Geomicrobiol. J. 36, 1-17 (2019).

48. Briegel, C. \& Seto, J. Single Amino Acids as Additives Modulating $\mathrm{CaCO}_{3}$ Mineralization. Chapter, 2. Advanced Topics in Biomineralization (2012).

49. Ivanov, V., Chu, J. \& Stnikov, V. Basics ofconstruction microbial biotechnology. In Biotechnologies and biomimetics for civil engineering. eds. Pacheco-Torgal, F., Labrincha, J. A., Diamanti, M. V., Yu, C.-P. \& Lee, H. K.), 21-56. Berlin, Germany:Springer (2014).

50. Li, Y., Katzmann, E., Borg, S. \& Schüler, D. The Periplasmic Nitrate Reductase Nap Is Required for Anaerobic Growth and Involved in Redox Control of Magnetite Biomineralization in Magnetospirillum gryphiswaldense. J. Bacteriol. 194, 4847-4856 (2012).

51. Roussel-Delif, L. et al. Frequency and Diversity of Nitrate Reductase Genes among Nitrate-Dissimilating Pseudomonas in the Rhizosphere of Perennial Grasses Grown in Field Conditions. Microbial Ecology 49, 63-72 (2005).

52. Daskalakis M. et al. Vaterite bio-precipitation induced by Bacillus pumilus isolated from a solutional cave in Paiania, Athens, Greece. Inter. Biodeterior. \& Biodegrad. 99 (2015).

53. Chou, C. et al. Biocalcification of Sand through Ureolysis. Journal of Geotechnical and Geoenviron. Eng. 137, 1179-1189 (2011).

54. Li, W. et al. Calcite precipitation induced by bacteria and bacterially produced carbonic anhydrase. Curr. Sci. 100, 502-508 (2011).

55. Singh, M. Urease activity and deposition of calcium carbonate layers on a 16th century Mughal monument. Curr. Sci. 116, 840-1849 (2019).

56. Anbu, P., Kang, C., Shin, Y. \& So, J. Formations of calcium carbonate minerals by bacteria and its multiple applications. SpringerPlus 5 (2016).

57. Desrosiers, M., Gately, L., Gambel, A. \& Menick, D. Purification and characterisation of the Ca2+ATPase of Flavobacterium odoratum. J. Biol. Chem. 271, 3945-3951 (1996).

58. Norris, V. et al. Calcium signalling in bacteria. J. Bacteriol. 178, 3677-3682 (1996).

59. Trushina, D., Bukreeva, T., Kovalchuk, M. \& Antipina, $\mathrm{M}$. $\mathrm{CaCO}_{3}$ vaterite microparticles for biomedical and personal care applications. Mate. Sci. \& Eng. C (2014).

60. Sdiri, A. \& Higashi, T. Simultaneous removal of heavy metals from aqueous solution by natural limestones. Appl. Water Sci. 3, 29-39 (2013).

61. Mugwar, A. \& Harbottle, M. Toxicity effects on metal sequestration by microbially-inducedcarbonate precipitation. J. Hazard. Mat. 314, 237-248 (2016).

62. Du, Y., Lian, F. \& Zhu L. Biosorption of divalent Pb, Cd and Zn on aragonite and calcite mollusk shells. Environ. Pollut. 159 (2011).

63. Cheng, W. Selective removal of divalent cations by polyelectrolyte multilayer nanofiltration membrane: Role of polyelectrolyte charge, ion size, and ionic strength. J. Membr. Sci. 559, 98-106 (2018).

64. Bohli, T., Villaescusa, I. \& Ouederni, A. Comparative Study of Bivalent Cationic Metals Adsorption $\mathrm{Pb}$ (II), $\mathrm{Cd}(\mathrm{II}), \mathrm{Ni}(\mathrm{II})$ and $\mathrm{Cu}(\mathrm{II})$ on Olive Stones Chemically Activated Carbon. J. Chem. Eng. \& Process Technol. 4, 1-7 (2013).

65. Zhang, X., Hao, Y., Wang, X., Chen, Z. \& Li, C. Competitive Adsorption of Cadmium(II) and Mercury(II) Ions from Aqueous Solutions by Activated Carbon from Xanthoceras sorbifolia Bunge Hull. J. Chem. 2016 (2016).

66. Chada, V., Hausner, D., Strongin, D., Rouff, A. \& Reeder, R. Divalent Cd and Pb uptake on calcite $\{10.14\}$ cleavage faces: An XPS and AFM study. J. Colloid \& Interface Sci. 288, 350-360 (2005).

67. Qian, X., Fang, C., Huang, M. \& Achal, V. Characterization of fungal-mediated carbonate precipitation in the biomineralization of chromate and lead from an aqueous solution and soil. J. Clean. Prod. 164, 198-208 (2017).

68. Irawati, W., Soraya, P. \& Baskoro, A. A Study on Mercury-Resistant Bacteria Isolated from a Gold Mine in Pongkor Village, Bogor, Indonesia. J. Biosci. 19, 197-200 (2012).

69. Halttunen, T., Salminen, S. \& Tahvonen, R. Rapid removal of lead and cadmium from water by specific lactic acid bacteria. Inter. J. Food Microbiol. 114, 30-35 (2007).

70. Newbury, D. Mistakes Encountered During Automatic Peak Identification of Minor and Trace Constituents in Electron-Excited Energy Dispersive X-Ray Microanalysis. Scanning 3, 91-101 (2009).

71. François, F. et al. Isolation and Characterization of Environmental Bacteria Capable of Extracellular Biosorption of Mercury. Appl. \& Environ. Microbiol. 78, 1097-1106 (2011).

72. Zaki, S., Eltarahony, M. \& Abd-El-Haleem, D. Disinfection of water and wastewater by biosynthesized magnetite and zerovalent iron nanoparticles via NAP-NAR enzymes of Proteus mirabilis 10B. Environ. Sci. \& Pollut. Res. 26, 23661-23678 (2019).

73. Han, Z., Yu, W., Zhao, Y., Tucker, M. \& Yan, H. The Significant Role of Different Magnesium: Carbonate Minerals Induced by Moderate Halophile Staphylococcus epidermis Y2. Minerals 8, 594 (2018).

74. Seifan, M., Samani, A. \& Berenjian, A. New insights into the role of $\mathrm{pH}$ and aeration in the bacterial production of calcium carbonate (CaCO3). Appl Microbiol Biotechnol. 101, 3131-3142 (2017).

75. Rothenstein, D., Baier, J., Schreiber, T., Barucha, V. \& Bill, J. Influence of zinc on the calcium carbonate biomineralization of Halomonas halophile. Aquatic Biosystems. 8, 1-13 (2012).

76. Silva-Castro, G. et al. Bioprecipitation of Calcium Carbonate Crystals by Bacteria Isolated from Saline Environments Grown in Culture Media Amended with Seawater and Real Brine. BioMed Res. Inter. 2015, 1-13 (2015).

77. Ghosh, T., Bhaduri, S., Montemagno, C. \& Kumar, A. Sporosarcina pasteurii can form nanoscale calcium carbonate crystals on cell surface. PLoS One 14, 1-15 (2019). 
78. Svenskaya, Y. et al. Key Parameters for Size- and Shape-Controlled Synthesis of Vaterite Particles. Cryst. Growth Des. 18, 331-337 (2018).

79. Tas, A. Monodisperse Calcium Carbonate Microtablets Forming at $701 \mathrm{C}$ in Prerefrigerated CaCl2-Gelatin-Urea Solutions. Int. J. Appl. Ceram. Technol. 6, 53-59 (2009).

80. Han, Z., Li, D., Zhao, H., Yan, H. \& Li, P. Precipitation of Carbonate Minerals Induced by the Halophilic Chromohalobacter Israelensis under High Salt Concentrations: Implications for Natural Environments. Minerals 7, 1-27 (2017).

81. Achal, V., Pan, X., Fu, Q. \& Zhang, D. Biomineralization based remediation of As(III) contaminated soil by Sporosarcina ginsengisoli. J. Haz. Mat. 201, 178-184 (2012).

82. Sun, J., Zhu, W. \& Huang, J. Characterization of primary precipitate composition formed during co-removal of $\mathrm{Cr}(\mathrm{VI})$ with $\mathrm{Cu}(\mathrm{II})$ in synthetic wastewater. Environ. Sci. Pollut. Res. 13, 379-385 (2006).

83. Singh, N. \& Gupta, D. Adsorption of Heavy Metals: A Review. Inter. J. Innov. Res. Sci., Eng. \& Technol. 5, 2267-2281 (2016).

84. Wang, L. \& Chen, Y. Sequential Precipitation of Iron, Copper, and Zinc from Wastewater for Metal Recovery. J. Environ. Eng. 145 (2019).

85. Pang, F., Teng, S., Teng, T. \& Omar, A. Heavy Metals Removal by Hydroxide Precipitation and Coagulation- Flocculation Methods from Aqueous Solutions. Water Qual. Res. J. Can. 44, 2 (2009).

86. Hu, H., Li, X., Huang, P., Zhang, Q. \& Yuan, W. Efficient removal of copper from wastewater by using mechanically activated calcium carbonate. J. Environ. Manag. 203, 1-7 (2017).

87. Fazlollahi, F., Zarei, M., Habashi, M. \& Baxter, L. Method for removal of mercury from oil field brine with calcium carbonat e coprecipitation. 131-138 (2014)

88. Azoddein, A., Yunus, R., Sulaiman, N., Bustary, A. \& Sabar, K. Mercury Removal Using Pseudomonas putida (ATTC 49128): Effect of Acclimatization Time, Speed and Temperature of Incubator Shaker. Inter. J. Biotechnol. \& Bioeng. 9, 204-209 (2015).

89. Eltarahony, M., Zaki, S., ElKady, M. \& Abd-El-Haleem D. Biosynthesis, Characterization of Some Combined Nanoparticles, and Its Biocide Potency against a Broad Spectrum of Pathogens. J. Nanomat. (2018).

90. Jun, Y. Effect of protein crud extract on oxic/anoxic diauxic growth of a NAP-deficient mutant of Paracoccus pantatrophus. M.Sc. thesis. University of Florida (2011).

91. Siddiqui, R. et al. Structure and function of a periplasmic nitrate reductase in Alcaligenes eutrophus H16. J. Bacteriol. 175, 5867-5876 (1993).

92. Ali, H. \& Al-Azzawi, Z. Ethanol production from date syrup. Academic Publishing. 24-26 (2010).

93. Standard Methods for the Examination of Water and Wastewater, American Public Health Association: American Water Works Association- Water Environment Federation (APHA, 1999).

94. Vashisht, R., Attri, S., Sharma, D., Shukla, A. \& Goel, G. Monitoring biocalcification potential of Lysinibacillus sp. isolated from alluvial soils for improved compressive strength of concrete. Microbiol. Res. 207, 226-231 (2018).

\section{Acknowledgements}

The authors acknowledge the Environmental Biotechnology Department, Genetic Engineering and Biotechnology Research Institute (GEBRI), City of Scientific Research and Technological Applications (SRTACity), New Borg El-Arab, Alexandria, Egypt. The authors gratefully thank Eng. Ayman Kamal for his help in mineralogical analysis of the samples.

\section{Author contributions}

M.E. proposed the research concept, design \& perform the experiments, carried out the statistical analysis, analyzed and interpreted the data and contributed substantially to the writing and revising of the manuscript. S.Z. conducted equations, provided some necessary tools for experiments and had given final approval of the version to be published. D.A. proposed the research concept, designed the experiments, contributed to reviewing process and had given final approval of the version to be published. All authors read and approved the final manuscript.

\section{Competing interests}

The authors declare no competing interests.

\section{Additional information}

Supplementary information is available for this paper at https://doi.org/10.1038/s41598-020-60951-1.

Correspondence and requests for materials should be addressed to M.E.

Reprints and permissions information is available at www.nature.com/reprints.

Publisher's note Springer Nature remains neutral with regard to jurisdictional claims in published maps and institutional affiliations.

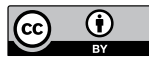

Open Access This article is licensed under a Creative Commons Attribution 4.0 International License, which permits use, sharing, adaptation, distribution and reproduction in any medium or format, as long as you give appropriate credit to the original author(s) and the source, provide a link to the Creative Commons license, and indicate if changes were made. The images or other third party material in this article are included in the article's Creative Commons license, unless indicated otherwise in a credit line to the material. If material is not included in the article's Creative Commons license and your intended use is not permitted by statutory regulation or exceeds the permitted use, you will need to obtain permission directly from the copyright holder. To view a copy of this license, visit http://creativecommons.org/licenses/by/4.0/.

(C) The Author(s) 2020 